\title{
A New Variable-Threshold Persistent Anomaly Index: Northern Hemisphere Anomalies in the ERA-Interim Reanalysis
}

\author{
Rebecca L. Miller, Gary M. Lackmann, And Walter A. Robinson \\ Department of Marine, Earth, and Atmospheric Sciences, North Carolina State University, Raleigh, North Carolina
}

(Manuscript received 8 May 2019, in final form 21 August 2019)

\begin{abstract}
Persistent weather regimes characterized by anomalous temperature or precipitation are often associated with persistent anomalies (PAs) in the tropospheric geopotential height field. To identify PAs throughout the annual cycle, an earlier definition is modified to apply a seasonally varying magnitude threshold, based on a smoothed, daily varying climatological average of daily 500-hPa geopotential height variability. The modified index can be applied to a wide variety of analysis, reanalysis, or model-forecast gridded data. Here, the modified PA index is used to identify positive and negative Northern Hemisphere PAs in all seasons and to compute trends in PA frequency, strength, location, and duration, in the ECMWF ERA-Interim reanalysis dataset (1979-2016). Height data are detrended and anomalies are weighted with an inverse sine-of-latitude function. In addition to maxima in PA frequency identified previously (North Pacific, North Atlantic, and Russia), an additional summertime maximum appears in the Arctic; this feature has not been analyzed extensively. A composite of summertime positive Arctic PA events reveals an equivalent barotropic structure, similar to that documented for midlatitude PAs. Arctic PA frequency is greatest in summer; it exhibits no trend in frequency over the 38-yr ERA-Interim analysis period. In fact, no discernable trends in PA frequency, strength, or duration are evident in the analysis period for the primary PA regions, although there is a suggestion of a northward shift in positive PA activity in the North Pacific.
\end{abstract}

\section{Introduction}

Persistent geopotential height anomalies (PAs) are often associated with highly impactful weather events, such as prolonged extreme temperatures and anomalous heavy precipitation or drought (e.g., Rex 1950b, 1951; Green 1977; Hong et al. 2011; Matsueda 2011; Sillmann et al. 2011; Pfahl and Wernli 2012; Grams et al. 2017). An example of such an event is the 2010 Russian heat wave that caused $\sim \$ 15$ billion (U.S. dollars) in Russian economic losses and thousands of fatalities (Barriopedro et al. 2011; Dole et al. 2011; Matsueda 2011). This event was associated with the occurrence of multiple positive PAs (i.e., atmospheric blocks) over Europe during the summer of 2010. The occurrence of these extreme warm-season heat events and their association with PAs is one of our motivations for seeking tools to optimize their detection and analysis.

An atmospheric block (e.g., Rex 1950a) is a feature that persistently disrupts the normal eastward progression of midlatitude weather systems by reversing or

\footnotetext{
Corresponding author: Rebecca L. Miller, rlmille7@ncsu.edu
}

suppressing the usual zonal flow. These events are most likely to form where the climatological flow is relatively weak and diffluent, such as downstream of the midlatitude storm tracks on the eastern side of the North Pacific and North Atlantic basins (e.g., Rex 1950a; Dole and Gordon 1983, hereafter DG83). Positive PAs, though not dynamically synonymous with blocks, are often associated with blocking. ${ }^{1}$ DG83 define a PA as a height anomaly that meets a fixed magnitude threshold and persists for a specified duration. In contrast to several blocking definitions (e.g., Tibaldi and Molteni 1990; Pelly and Hoskins 2003), this definition of a PA does not require a reversal of the meridional gradient in the height or potential vorticity (PV) field. Some PAs feature flow patterns that do not resemble blocking, such as those associated with significant, persistent meridional shifts in the jet stream position; these events are also of interest.

There are many different objective definitions and detection algorithms for identifying blocks and PAs;

\footnotetext{
${ }^{1}$ Blocking can be accompanied by either cyclonic or anticyclonic flow, as defined in the AMS Glossary of Meteorology (American Meteorological Society 2019).
} 


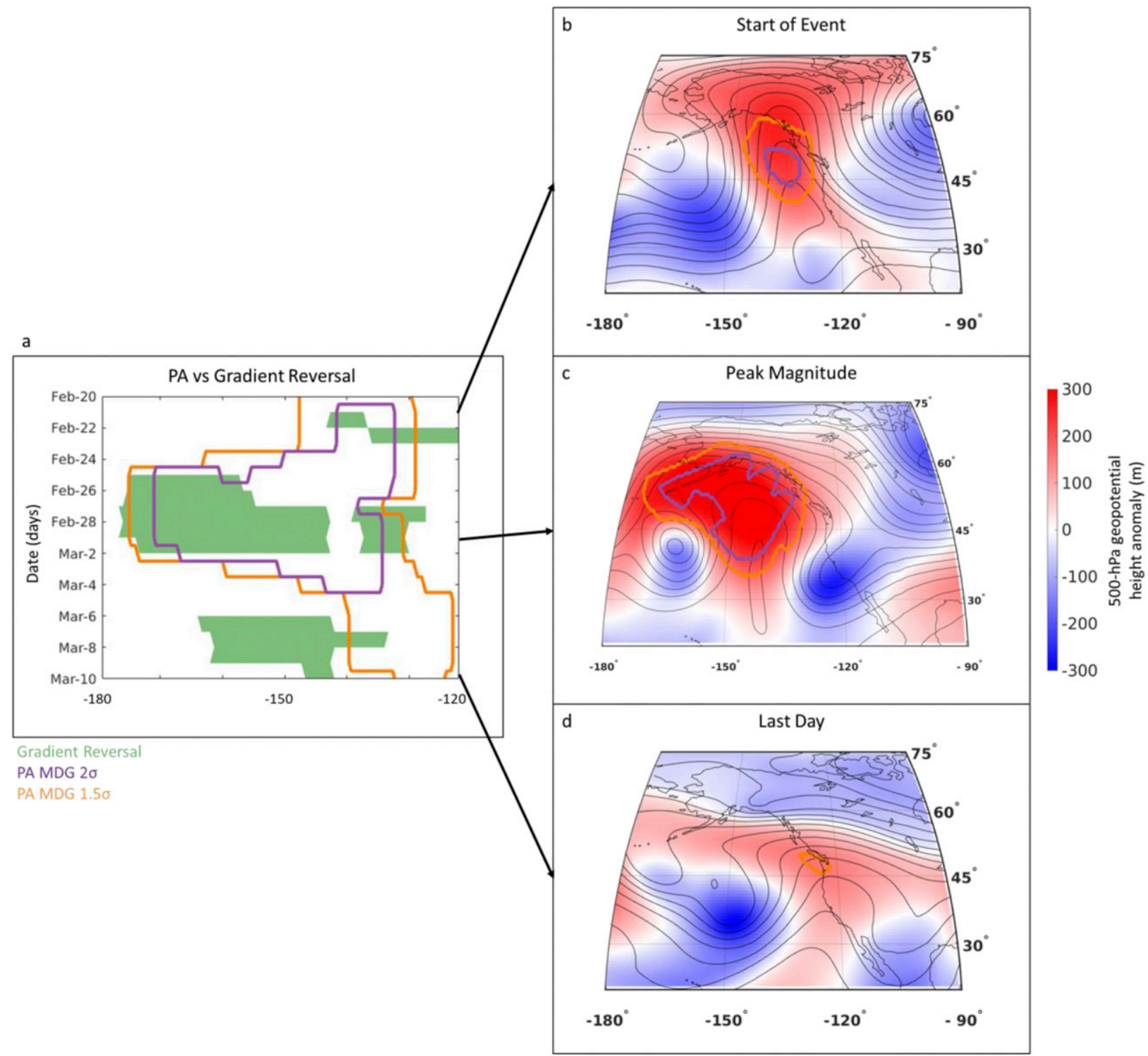

FIG. 1. Life cycle of a PA event that occurred in the Pacific, February-March 2015. (a) Hovmöller diagram of the PA event and its gradient reversal in the $40^{\circ}-70^{\circ} \mathrm{N}$ latitude band (shaded green). The PA is identified using a daily varying magnitude threshold of 1.5 and 2 standard deviations of the 500-hPa geopotential height anomaly (contoured orange and purple, respectively) and the gradient reversal is identified using the Tibaldi and Molteni (1990) method. (b)-(d) Snapshots of the event: (b) start of event, 21 Feb; (c) peak magnitude, 1 Mar; and (d) last day of event, 20 Mar. (right) 500-hPa geopotential height (black, contour interval 60 gpm) and 500-hPa geopotential height anomaly ( $\mathrm{m}$, shaded as in legend).

here we illustrate why we selected the approach of DG83. Figure 1 depicts a PA event without a persistent reversal of the gradient in the height field between $40^{\circ}$ and $70^{\circ} \mathrm{N}$, which, at times would not be identified as a block using definitions that require such a reversal (e.g., Tibaldi and Molteni 1990). This PA event contributed to anomalous warm conditions in the western United States during a portion of the winter of 2015 (NOAA/National Centers for Environmental Information 2015a,b). Using the DG83 PA definition with a daily varying magnitude threshold described in section 2 , this event is identified 5 days before the maximum reversal in gradient, which occurs when the event is at or nearing peak magnitude (Fig. 1c). Requiring the existence of a gradient reversal in this case would prevent the identification of the early stages of the event life cycle, despite having attained a large amplitude. In contrast, the approach of DG83 captures the entire life cycle of the PA event, and thus offers the opportunity to understand its initiation, evolution, and demise. Another anomaly-based 
index, based on PV, is that of Schwierz et al. (2004). This index also captures the entire life cycle without the requirement of a gradient reversal, as it identifies the PA using the vertically averaged PV to capture the anomaly near the dynamic tropopause (Schwierz et al. 2004; Croci-Maspoli et al. 2007). However, the efficiency and convenience of an index based on a single variable at a single level leads us to favor the approach of DG83.

As the above example illustrates, the approach of DG83 identifies shifts in the jet and poleward extensions of anticyclones, as well as blocks. Barriopedro et al. (2010) provide an overview of several identification techniques for blocks and PAs, discuss the strengths and weaknesses of the most common methods (e.g., DG83; Tibaldi and Molteni 1990), and introduce their own novel detection of blocks, which is a combination of prior methods. Throughout the remainder of this paper, we will use the terms block and PA interchangeably, although we recognize that PA is a broader term that includes some features that do not correspond to the traditional definition of a block. Because the definition of PAs requires persistence and amplitude that exceed given thresholds, without constraints on spatial structures, in addition to blocks, PAs will include a portion of the overall low-frequency variability of the extratropical atmosphere (Barnston and Livezey 1987; Kushnir and Wallace 1989). For example, the lobes of some highamplitude occurrences of teleconnection patterns (Wallace and Gutzler 1981) will be identified as PAs. Moreover, teleconnections can modulate the occurrence of blocking (Renwick and Wallace 1996). Thus, lowfrequency variability, blocking, and persistent anomalies are overlapping though distinct phenomena.

To identify a height anomaly as a PA, the DG83 method requires magnitude and duration thresholds. DG83 used fixed thresholds that are most applicable to winter months. Application of a fixed, winter-based threshold to other seasons identifies very few warmseason events, owing to the generally weaker variability in heights during the warm season. To study potentially impactful PAs across the annual cycle, with a representative number of PAs in all seasons, a time-varying PA amplitude threshold is advantageous. Several previous studies have recognized the need for seasonally varying event thresholds. The identification methods developed by Barriopedro et al. (2010) combine those of Tibaldi and Molteni 1990, Pelly and Hoskins (2003), and DG83. For PA identification, their magnitude threshold applied to a calendar month is computed as one standard deviation of the daily height anomalies within that month. Dunn-Sigouin and Son (2013) use methods similar to those of Barriopedro et al. (2010) but increase the threshold to 1.5 standard deviations. Grams et al.
(2017) use a running 30-day window of 500-hPa height standard deviation to define event thresholds in their analysis of persistent European weather regimes. To provide a temporally continuous identification of PAs throughout the year, our study uses a daily varying threshold as described in section 2. The magnitude threshold is adjustable to any user-defined multiple of the standard deviation.

Previously identified regions of maxima in Northern Hemisphere (hereafter NH) PA frequency are the North Pacific, North Atlantic, and Russia (e.g., DG83). However, with our modified DG83 index (hereafter MDG), an additional maximum in PA frequency is evident in the Arctic, specifically in summer. ${ }^{2}$ The main purposes of this paper are to present our variablethreshold PA index, apply the modified index to a modern reanalysis dataset in order to evaluate the method, assess trends in PA activity, and to present preliminary analysis of the Arctic PA maximum. Details regarding our index are provided in section 2 . In section 3 we compare results using this and DG83's original method, and we present trends and seasonal climatologies of PAs computed using the modified index. Section 3 also presents a preliminary analysis of Arctic PA events. Conclusions and suggested future applications of the modified PA index are discussed in section 4 .

\section{Data and methods: The modified Dole and Gordon (MDG) index}

\section{a. Data}

The primary source of data for this study is the European Centre for Medium-Range Weather Forecasts (ECMWF) interim reanalysis (ERA-Interim, hereafter ERAI; Dee et al. 2011), which features an approximate grid spacing of $0.7^{\circ} \times 0.7^{\circ}$; we use the 6-hourly and daily average 500-hPa geopotential height field from 1 January 1979 to 31 December 2016. First, we compute the 38-yr climatological mean (1979-2016) daily average geopotential height for every grid point. Once this daily average is computed, we apply a fifth-order, 8-week low-pass Butterworth filter (e.g., Robertson and Dowling 2003) to remove high-frequency temporal variations and obtain a smooth day-to-day annual cycle $\left(\bar{Z}_{f}\right)$.

To account for the potential effect of changes in the background climate over the past 38 years, heights are detrended over the period of the record. From the daily

\footnotetext{
${ }^{2}$ Three-month meteorological seasons are defined as follows: December-January-February (winter), March-April-May (spring), June-July-August (summer), and September-October-November (fall).
} 
500-hPa geopotential heights $(Z)$, we detrend $\left(Z_{\text {DeT }}\right)$ the heights by subtracting a trend correction $\left(Z_{C}\right)$ defined as the difference between the least squares fit $\left(Z_{\mathrm{LS}}\right)$ over the time series and the mean $(\bar{Z})$ at each grid point for each day:

$$
\begin{gathered}
Z_{\mathrm{DeT}}=Z-Z_{C}, \\
Z_{C}=Z_{\mathrm{LS}}-\bar{Z} .
\end{gathered}
$$

To obtain a smooth time series, $Z_{C}$ is filtered with the Butterworth filter. The daily height anomaly $\left(Z^{\prime}\right)$ is calculated as follows:

$$
Z^{\prime}=\frac{\sin \left(45^{\circ}\right)}{\sin (\varphi)}\left(Z_{\mathrm{DeT}}-\bar{Z}_{f}\right)
$$

where $\varphi$ is the latitude of the grid point, and $Z^{\prime}$ is normalized by latitude as in DG83 to eliminate the bias toward high latitudes and to better represent atmospheric energy dispersion as motivated by Hoskins et al. (1977). Note that detrending the height prior to anomaly calculation is critical for assessing trends in PA activity, as it is trends in anomalies that are of interest. There is an overall positive trend in the average height due to warming during the 38-yr time series. If heights were not detrended, the analysis would, therefore, indicate spurious trends in the occurrence of PAs, with more negative PAs near the beginning of the analysis period and more positive PAs near its end.

\section{b. Identification index}

To identify whether a given anomaly in the geopotential height field qualifies as a PA, we compute and apply a temporally varying magnitude threshold and a fixed duration threshold to the time series of anomaly values. The temporally varying magnitude threshold $(\sigma)$ is the standard deviation of $Z^{\prime}$ updated daily within a 4-week window centered on the day of interest ( 29 days) for all years:

$$
\begin{aligned}
\sigma= & \operatorname{std}\left[\left(Z_{d-14}^{\prime}, \ldots, Z_{d}^{\prime}, \ldots, Z_{d+14}^{\prime}\right)_{1979}, \ldots,\right. \\
& \left.\left(Z_{d-14}^{\prime}, \ldots, Z_{d}^{\prime}, \ldots, Z_{d+14}^{\prime}\right)_{2016}\right],
\end{aligned}
$$

where $d$ is a single day of interest. Last, $\sigma$ is averaged over the $\mathrm{NH}\left(20^{\circ}-90^{\circ} \mathrm{N}\right) .^{3}$ By using the hemisphericaverage magnitude threshold, we apply a simple,

\footnotetext{
${ }^{3}$ An alternate approach would be to apply the magnitude threshold separately at every grid point (without applying a hemispheric average), so as to define thresholds relative to the local dynamic climatology. However, this would result in spatially varying dynamical magnitude, which was not desirable for our purposes.
}

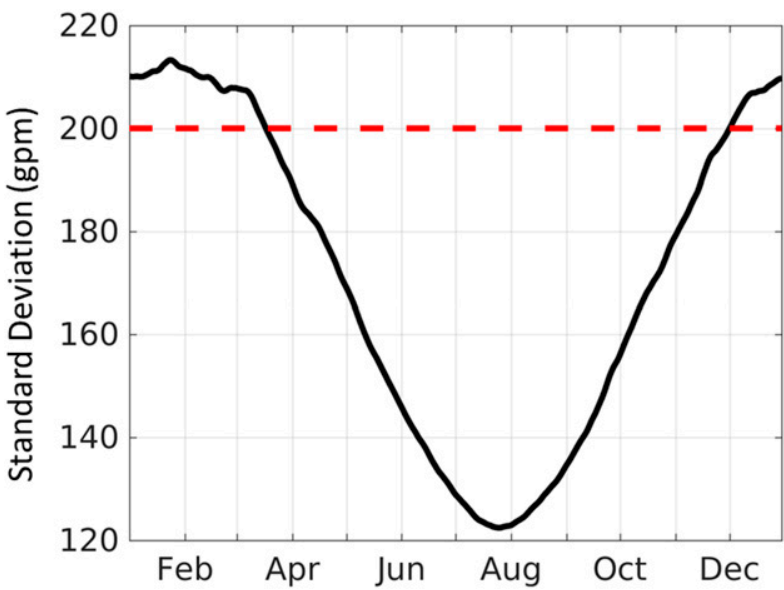

FIG. 2. Derived magnitude threshold: NH daily average 500-hPa geopotential height anomaly standard deviation. Derived $2 \sigma$ threshold from ERAI (black solid line) and a 200-m set threshold (red dashed line).

computationally efficient definition that is analogous to the approach of DG83, except with a daily varying magnitude threshold based on the hemispherically averaged standard deviation.

The anomaly threshold can be set to any multiple $n$ of the standard deviation, and the duration threshold could likewise be adjusted. At a given grid point, a PA is identified when the local anomaly exceeds the specified multiple, $n$, of the standard deviation magnitude threshold and persists for at least $d$ days $(n= \pm 1.0,1.5$, $2.0, \ldots, d=4,5,6,7, \ldots)$. The daily varying threshold values are compared to a fixed 200-m threshold, applicable to winter months, in Fig. 2. Here, we use $n=2 \sigma$ and $d=5$ days; experimentation revealed that these settings provide clear spatial separation of regional PA frequency maxima.

To account for the spatial coherence of PAs, we combine contiguous PA regions with centroids within $2000 \mathrm{~km}$ of each other that occur within one day. Centroids are taken as the three-dimensional (latitude, longitude, time) centroid for the identified grouping of PA grid points. Once PA events have been identified, we compute event characteristics such as the duration, mean and maximum event magnitude, and the average spatial extent. For the seasonal analysis of PAs, the threemonth meteorological seasons are used. PA events are assigned to a season based on the occurrence of the first day of the event. Note that our identification index can easily be applied to the Southern Hemisphere with appropriate alterations. For brevity, we limit our analysis to the $\mathrm{NH}$; both positive (hereafter $+\mathrm{PA}$ ) and negative (hereafter $-\mathrm{PA}$ ) events are considered.

To compare regional event characteristics, we define locations corresponding to distinct maxima in the spatial 
(a) MDG $+2 \sigma$
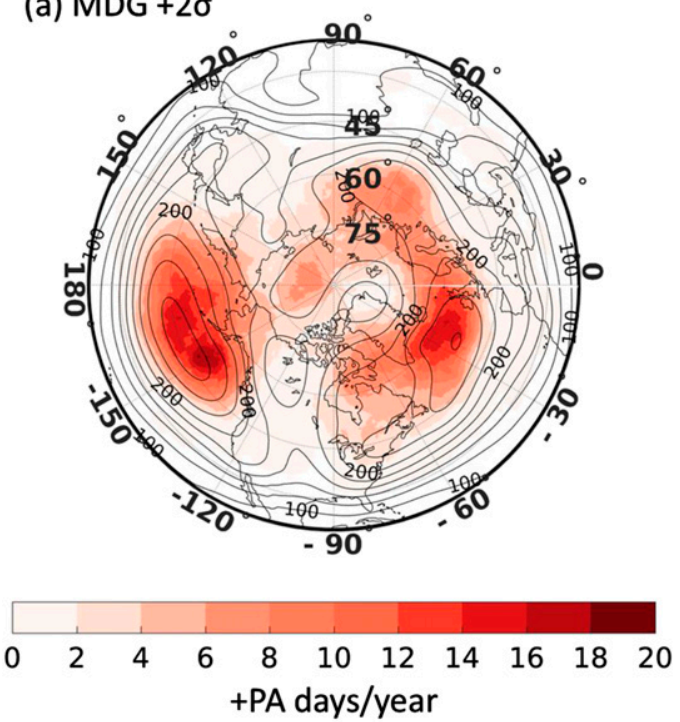

(c)

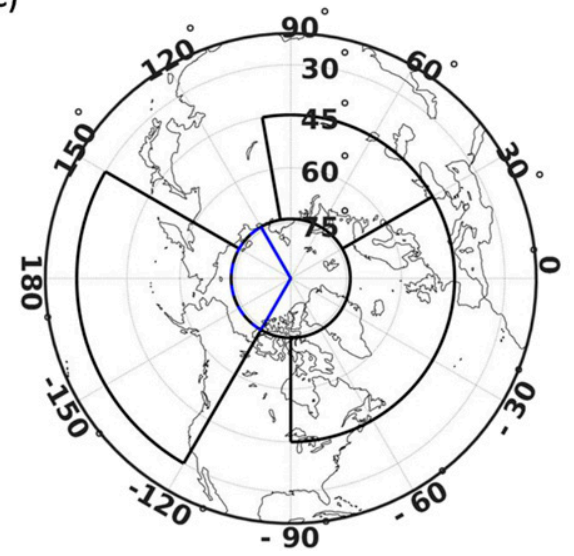

distribution of PA frequency (Fig. 3c). These regions include the North Pacific $\left(30^{\circ}-74^{\circ} \mathrm{N}, 150^{\circ} \mathrm{E}-120^{\circ} \mathrm{W}\right)$, the North Atlantic and Europe $\left(45^{\circ}-74^{\circ} \mathrm{N}, 90^{\circ} \mathrm{W}-30^{\circ} \mathrm{E}\right)$, Russia $\left(45^{\circ}-74^{\circ} \mathrm{N}, 30^{\circ}-100^{\circ} \mathrm{E}\right)$, and the Arctic $\left(74^{\circ}-\right.$ $\left.90^{\circ} \mathrm{N}\right)$. We provide additional analysis of the Arctic PA maximum, a feature that has received limited documentation in previous studies, and which may hold additional significance in the context of climate change and its polar amplification (e.g., Wernli and Papritz 2018).

\section{c. Arctic summer event composite}

We composite summer + PA events to elucidate the structure and life cycle of PAs that comprise the summer Arctic maximum. There are 79 summertime Arctic events during the analysis period; to provide a more restrictive spatial focus in compositing, we isolate 37 events that had at least $50 \%$ of their footprint within a more confined Arctic subregion $\left(74^{\circ}-90^{\circ} \mathrm{N}\right.$, (b) MDG $-2 \sigma$
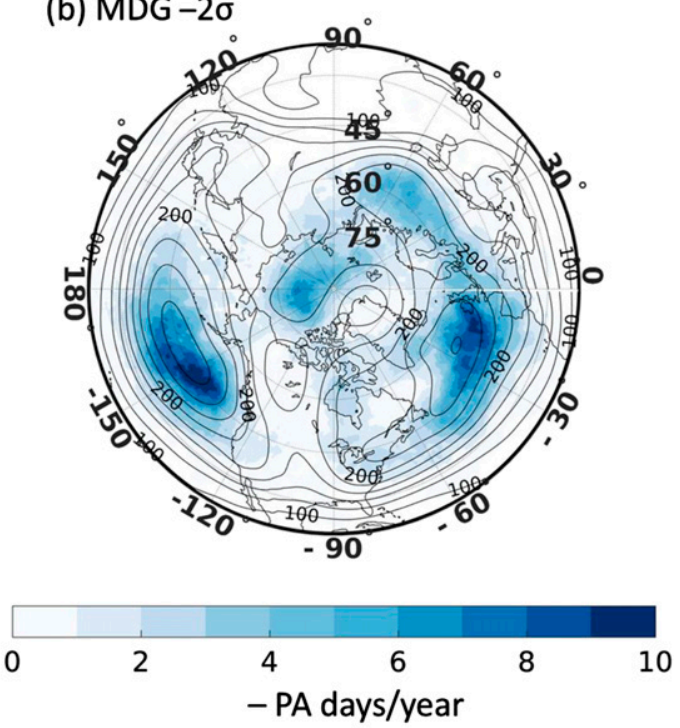

FIG. 3. Annual $\pm \mathrm{PA}$ days over the 38 -yr time series. (a) + PA days per year (red, shaded as in legend); (b) -PA days per year (blue, shaded as in legend). PAs shown here identified with MDG $\pm 2 \sigma$ (contoured $2 \sigma$ standard deviation every $20 \mathrm{gpm}$ ). (c) Region boundary definitions (black) and the Arctic composite region (blue).

$120^{\circ} \mathrm{E}-120^{\circ} \mathrm{W}$; Fig. $\left.3 \mathrm{c}\right)$; one event with a very small spatial area was eliminated (no requirement is imposed for spatial extent). For two instances where events occurred within 7 days of each other, we eliminated the event with the weaker average magnitude. Table 1 lists the remaining 34 events that comprise the composite.

To provide a more complete dynamical description of the Arctic PA events, we generated composites of 500and $300-\mathrm{hPa}$ geopotential height, sea level pressure (SLP), zonal and meridional wind components $\left(u_{\text {Trop }}\right.$, $\left.v_{\text {Trop}}\right)$, and potential temperature on the dynamic tropopause (2 PVU; $\theta_{\text {Trop }}$ ). The $300-\mathrm{hPa}$ geopotential height and $\theta_{\text {Trop }}$ anomalies are calculated as described above for the $500-\mathrm{hPa}$ geopotential height anomaly, except that we do not detrend $\theta_{\text {Trop. }}$. Additionally, advection of $\theta_{\text {Trop }}\left(\theta_{\text {Trop_ADV }}\right)$ is computed as

$$
\theta_{\text {Trop_ADV }}=-u_{\text {Trop }} \frac{\partial \theta_{\text {Trop }}}{\partial x}-v_{\text {Trop }} \frac{\partial \theta_{\text {Trop }}}{\partial y} .
$$


TABLE 1. Arctic summer composite event list.

\begin{tabular}{|c|c|c|c|c|c|c|c|}
\hline & \multicolumn{3}{|c|}{ Start date } & \multicolumn{3}{|c|}{ End date } & \multirow{2}{*}{$\begin{array}{c}\text { Duration } \\
\text { (days) }\end{array}$} \\
\hline & Year & Month & Day & Year & Month & Day & \\
\hline 1 & 1979 & 6 & 21 & 1979 & 6 & 25 & 5 \\
\hline 2 & 1979 & 7 & 21 & 1979 & 8 & 2 & 13 \\
\hline 3 & 1979 & 8 & 17 & 1979 & 8 & 21 & 5 \\
\hline 4 & 1980 & 7 & 14 & 1980 & 7 & 18 & 5 \\
\hline 5 & 1984 & 7 & 11 & 1984 & 7 & 16 & 6 \\
\hline 6 & 1985 & 6 & 3 & 1985 & 6 & 16 & 14 \\
\hline 7 & 1985 & 7 & 7 & 1985 & 7 & 29 & 23 \\
\hline 8 & 1987 & 6 & 22 & 1987 & 7 & 6 & 15 \\
\hline 9 & 1988 & 6 & 30 & 1988 & 7 & 4 & 5 \\
\hline 10 & 1990 & 8 & 13 & 1990 & 8 & 25 & 13 \\
\hline 11 & 1991 & 6 & 8 & 1991 & 6 & 13 & 6 \\
\hline 12 & 1991 & 8 & 31 & 1991 & 9 & 11 & 12 \\
\hline 13 & 1992 & 6 & 24 & 1992 & 6 & 30 & 7 \\
\hline 14 & 1993 & 7 & 6 & 1993 & 7 & 10 & 5 \\
\hline 15 & 1993 & 8 & 21 & 1993 & 9 & 5 & 16 \\
\hline 16 & 1994 & 6 & 16 & 1994 & 6 & 28 & 13 \\
\hline 17 & 1995 & 7 & 3 & 1995 & 7 & 8 & 6 \\
\hline 18 & 1997 & 7 & 3 & 1997 & 7 & 7 & 5 \\
\hline 19 & 1999 & 8 & 5 & 1999 & 8 & 18 & 14 \\
\hline 20 & 2000 & 7 & 27 & 2000 & 8 & 2 & 7 \\
\hline 21 & 2000 & 8 & 24 & 2000 & 8 & 31 & 8 \\
\hline 22 & 2002 & 8 & 3 & 2002 & 8 & 11 & 9 \\
\hline 23 & 2005 & 6 & 29 & 2005 & 7 & 3 & 5 \\
\hline 24 & 2005 & 7 & 18 & 2005 & 8 & 1 & 15 \\
\hline 25 & 2006 & 7 & 2 & 2006 & 7 & 10 & 9 \\
\hline 26 & 2007 & 6 & 5 & 2007 & 6 & 16 & 12 \\
\hline 27 & 2007 & 7 & 15 & 2007 & 7 & 24 & 10 \\
\hline 28 & 2008 & 8 & 8 & 2008 & 8 & 15 & 8 \\
\hline 29 & 2009 & 6 & 29 & 2009 & 7 & 11 & 13 \\
\hline 30 & 2010 & 6 & 16 & 2010 & 6 & 29 & 14 \\
\hline 31 & 2011 & 7 & 3 & 2011 & 7 & 12 & 10 \\
\hline 32 & 2012 & 6 & 4 & 2012 & 6 & 11 & 8 \\
\hline 33 & 2013 & 7 & 9 & 2013 & 7 & 15 & 7 \\
\hline 34 & 2014 & 8 & 5 & 2014 & 8 & 17 & 13 \\
\hline
\end{tabular}

This quantity is composited to diagnose the poleward transport of low-PV air from lower latitudes into the +PA event region.

We construct the Arctic PA composite by averaging the variables in time over the entire event duration as well as for specific periods of interest for each event. To identify structures during different stages of the composite PA life cycle, we temporally centered composites for the first day of each event, the day of peak magnitude, and the last day of each event. To diagnose conditions leading to event onset, we also performed lagged composites going back 10 days prior to the first day of each event. The day of peak magnitude is determined by the daily average event anomaly.

\section{Results}

\section{a. Northern Hemisphere spatial frequency}

With our temporally varying magnitude threshold set to $2 \sigma$ and using a 5-day duration threshold, we identify four regional maxima in PA frequency over the 38-yr period of analysis (Fig. 3). These regions include the North Pacific, the North Atlantic, Russia, and the Arctic. The Pacific, Atlantic, and Russian regions were each identified by DG83. The annual MDG frequencies are greater than those from DG83, as expected, owing to an increased ability to identify events throughout the annual cycle. In the annual average, the regional North Pacific + PA maximum is centered south of the Aleutian Islands and stretches from $150^{\circ} \mathrm{E}$ to $120^{\circ} \mathrm{W}$, east of Japan to the west coast of North America (Fig. 3a). The North Atlantic + PA maximum occurs southeast of Greenland, extending eastward from Baffin Island in northeastern Canada to Greenland and into Europe. There is an extension of the North Atlantic maximum across Scandinavia into Russia, where another local maximum is observed near $60^{\circ} \mathrm{N}, 50^{\circ} \mathrm{E}$. The Arctic maximum is located between Siberia and the North Pole (Fig. 3a).

Relative to frequency maxima for $+\mathrm{PAs}$, the maxima in -PA occurrence exhibit a lower frequency (Fig. 3b). Despite a larger total number of -PA events (2279 - PA events versus 1835 + PA events), the spatial frequency map shows lower values for $-\mathrm{PAs}$ due to their smaller spatial extent (section 3c). The North Pacific, North Atlantic, and Russian -PA regions are shifted somewhat equatorward of the + PA centers, where strong cyclonic systems present as large negative height anomalies. Centers of positive and negative maxima in Arctic PA occurrence are collocated. Both positive and negative PA frequency maxima are generally collocated with regions of large average standard deviation; we find no examples of locations that exhibit a high number of annual PA days and low background values of the standard deviation (Figs. 3a,b). The largest PA frequencies are typically found at the eastern extent of regions of large standard deviation in the Pacific and Atlantic regions.

Using the MDG index allows us to examine the complete seasonal cycle of NH PA activity. The regional centers of large PA frequency of either sign exhibit considerable seasonal variation in frequency, magnitude, and spatial extent, similar to the seasonal variation of the standard deviation (Figs. 2, 4, and 5). The North Pacific +PA frequency maximum is meridionally broad, with greatest amplitude in winter and smallest in summer, similar to the seasonal standard deviation maximum in this region (Figs. 3a and 4). While the +PA frequency maxima match regions of largest standard deviation, $-\mathrm{PA}$ frequency maxima are preferentially located at the eastern extremities of the large standard deviation regions in the cool seasons (Figs. 4 and 5). During summer, the $-\mathrm{PA}$ frequency maxima are more closely aligned with regions of large standard deviation (Fig. 5c). 
(a) Winter

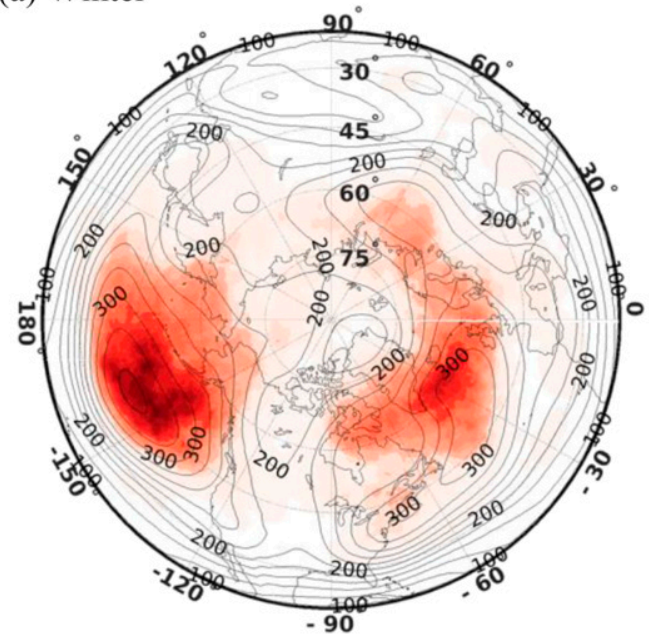

(c) Summer

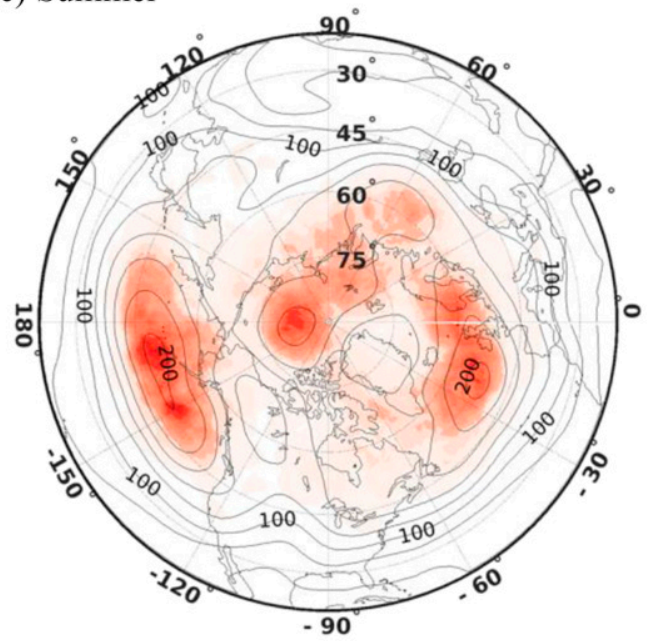

(b) Spring

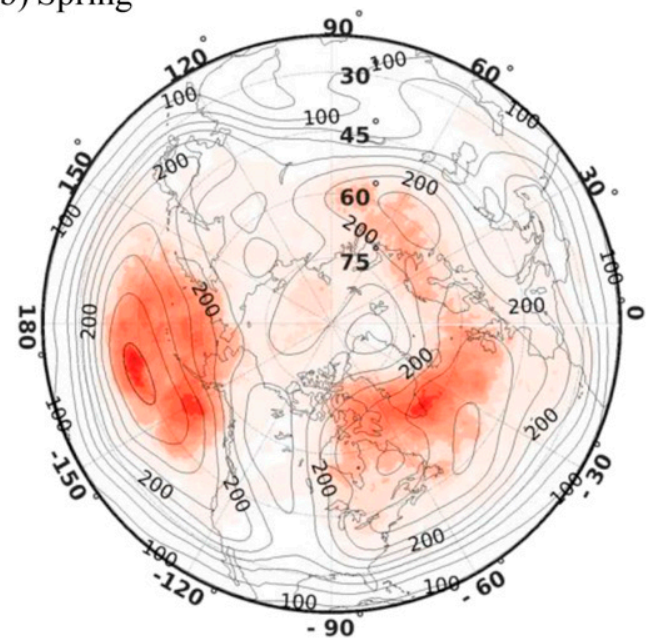

(d) Fall

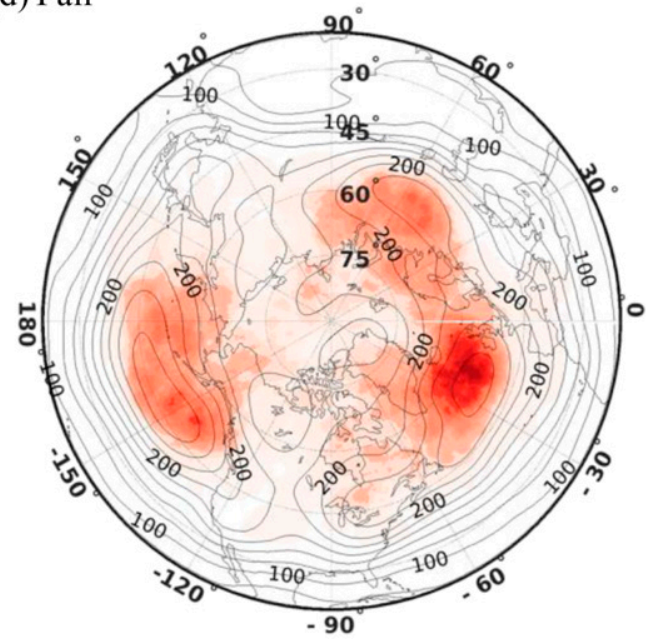

\section{$\begin{array}{llllllll}0 & 1 & 2 & 3 & 4 & 5 & 6 & 7\end{array}$ +PA days/year}

FIG. 4. Seasonal + PA days per year over the 38-yr time series using a threshold of $+2 \sigma ;+$ PA days per year (red, shaded as in legend) with contoured $2 \sigma$ standard deviation every $20 \mathrm{gpm}$.

Throughout the year, the North Atlantic + PA frequency maximum is centered to the north of the region of largest climatological standard deviation and is shifted relative to regions of large -PA frequency (Figs. 4 and 5). The Russian PA maximum is relatively weak compared to the North Atlantic and North Pacific maxima, and it reaches its peak amplitude in fall (Figs. $4 \mathrm{~d}$ and 5d). Unlike the other PA frequency maxima, the Arctic maximum appears only during summer, and features collocated positive and negative PA frequency maxima (Figs. $4 \mathrm{c}$ and $5 \mathrm{c}$ ).
To provide a meaningful comparison of MDG and DG83, Fig. 6 shows wintertime PA frequency computed using the fixed-threshold method of DG83; these plots are directly comparable to Figs. $4 \mathrm{a}$ and $5 \mathrm{a}$. Though overall very similar, the fixed-threshold DG83 method identifies more winter + PA days, owing to a slightly lower threshold relative to the variablethreshold MDG algorithm (cf. Figs. 4a and 6a). For -PA events, the patterns are again very similar, with slightly more -PA days in the North Pacific with the 
(a) Winter

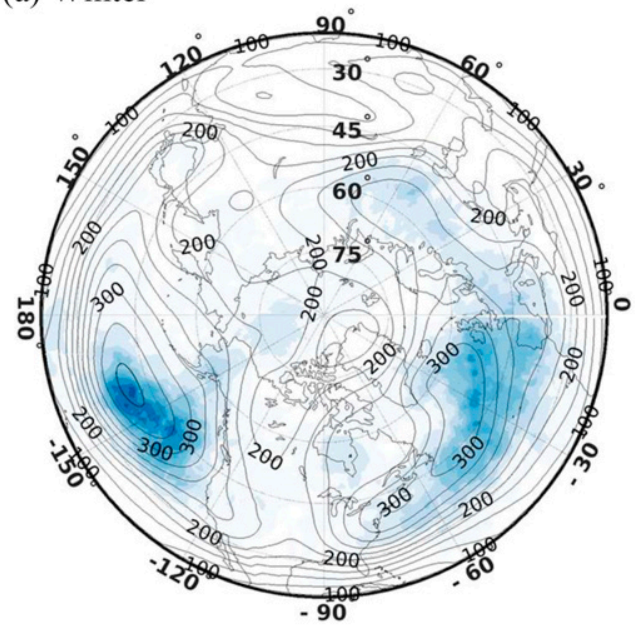

(c) Summer

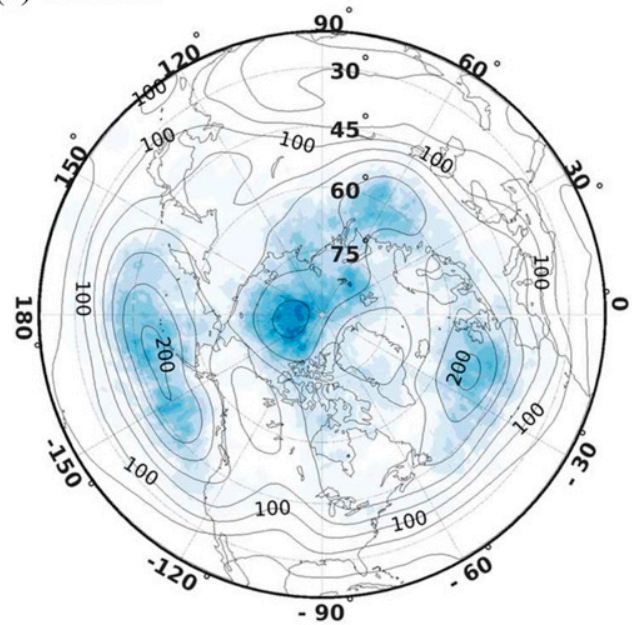

(b) Spring

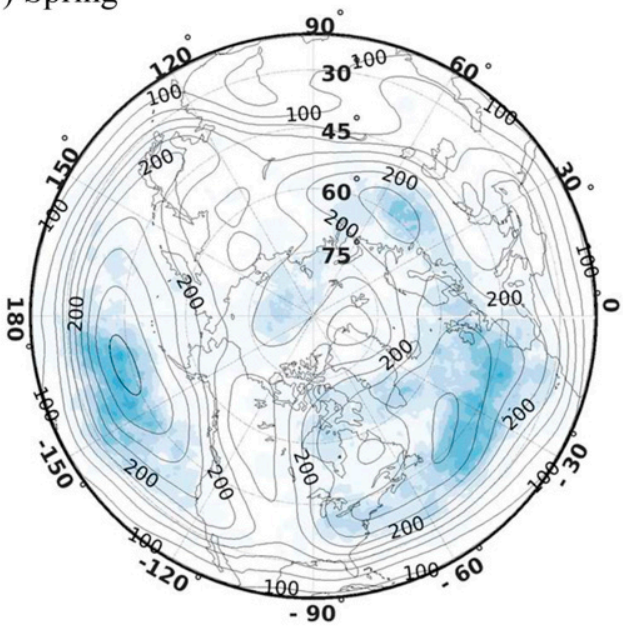

(d) Fall

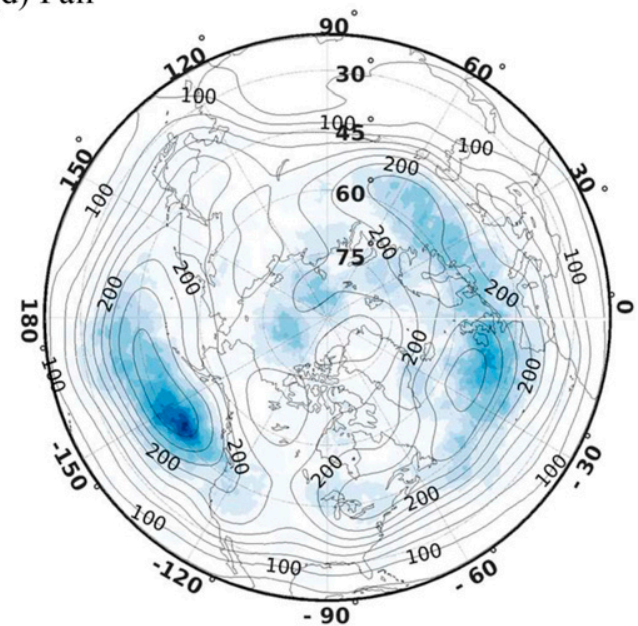

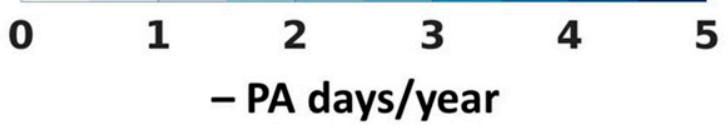

FIG. 5. Seasonal -PA days per year over the 38-yr time series using a threshold of $-2 \sigma ;-$ PA days per year (blue, shaded as in legend) with contoured $2 \sigma$ standard deviation every $20 \mathrm{gpm}$.

fixed-threshold setting, again consistent with the slightly lower threshold (Fig. 2).

\section{b. Northern Hemisphere PA trends}

Several previous studies have suggested possible increases in blocking in response to a reduction in Arctic sea ice (e.g., Francis and Vavrus 2015), while Wernli and Papritz (2018) argue that the occurrence of Arctic blocking may serve to modulate Arctic sea ice. Motivated by these findings, we investigate trends in PA activity during our 38-yr analysis period, including hemispheric and regional trends. Owing to warming over the analysis period, average values of the $500-\mathrm{hPa}$ height field increase during the analysis period. Thus, it is necessary to detrend the height field prior to the computation of anomalies, in order to preserve the dynamical consistency of the PAs.

For both positive and negative PA event frequency, we find no significantly robust trends in NH PA activity (i.e., $p$ values are $>0.05$; Figs. $7 \mathrm{a}, \mathrm{b}$ ). For $+\mathrm{PA}$ events there is a slight negative trend, and the trend in -PA frequency is nearly zero. Examination of all regional 
(a) DG83 +200 m winter

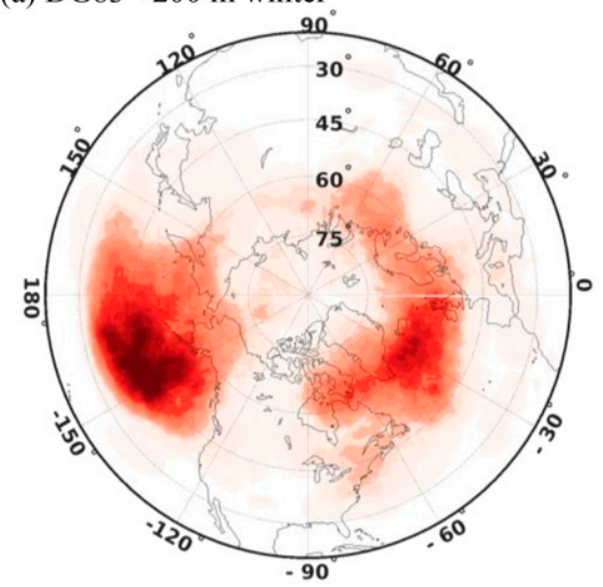

(b) DG83 -200 m winter

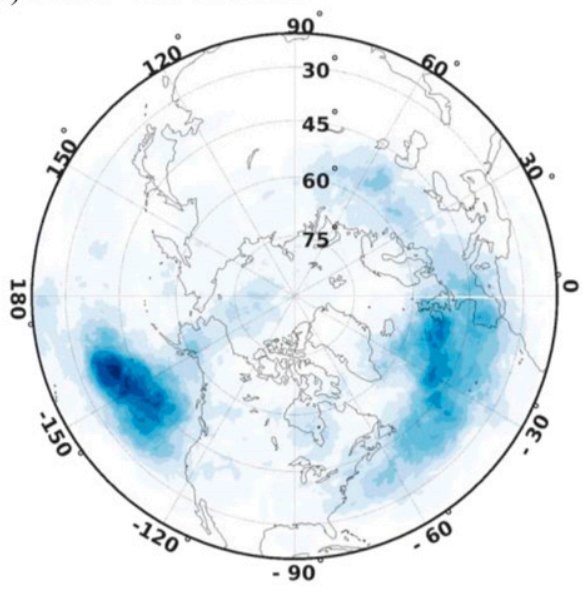

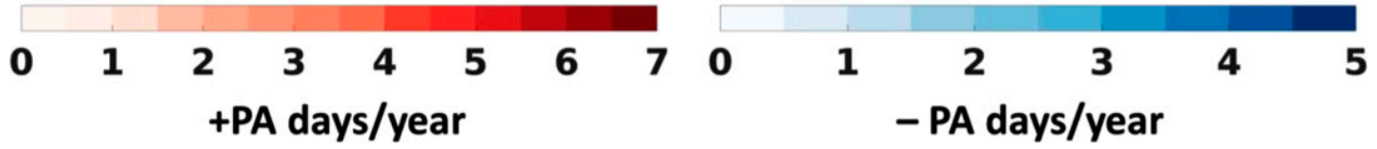

FIG. 6. Wintertime PA days per year over the 38-yr time series for a set $\pm 200-\mathrm{m}$ threshold as in DG83; (a) +PA days per year (red, shaded as in legend) and (b) -PA days per year (blue, shaded as in legend).

PA trends reveals that the frequency of positive Arctic PAs in summer exhibits a negative trend, while Arctic - PA events in that season display a smaller negative trend (Figs. $7 \mathrm{c}, \mathrm{d}$ ). These trends are small relative to interannual variability, however. The only significantly robust trend is a positive trend in the Atlantic fall - PA event frequency $(p$ value $=0.02$; Fig. $7 \mathrm{e})$. We find no apparent trends in the $\mathrm{NH}$ annual frequency of positive and negative PA events of a specific duration, magnitude, or spatial extent. To evaluate trends for a more complete measure of PA activity, we computed a combination PA strength metric, defined as the product of the event-average magnitude and the average spatial extent of PA events. Consistent with the above results, we find no trend in this quantity (not shown). Overall, the null hypothesis that PA frequencies are stationary in time cannot be rejected.

Figure 8 displays the geographical distribution of linear trends for both positive and negative PA days per year. For positive PA days, there is a region of significantly robust $(p$ value $<0.05$ ) negative trend in the North Pacific, south of a region of positive trend over Siberia and the Bering Sea, suggesting a poleward shift in +PA activity in this region over time (Fig. 8a). This calculation suggests a general increase in +PA days at higher latitudes, such as over Siberia and parts of Russia. The trends in -PA days are smaller, and noisier than the +PA day trends (Fig. 8b). Most notably, there is a region of positive trends in the central North Pacific and there are negative trends over the east Atlantic and parts of Europe for -PA days.

\section{c. Statistical analysis of event characteristics}

A total of $1835+$ PA events and $2279-$ PA events were identified in the Northern Hemisphere during the 38-yr study period. Duration statistics for these samples illustrate an approximate exponential drop-off (Fig. 9), consistent with red-noise characteristics (e.g., Feldstein 2000). Consistent with Dole (1982) and DG83, we expect -PA events to be less persistent than +PA events. Defining very long-duration events as those lasting more than 25 days, we find in the Arctic region that there are more long-duration -PA events than +PA events; these events primarily occur during summer (Fig. 10). The Arctic experiences the most very long-duration -PA events of all regions considered, accounting for $\sim 60 \%$ of all very long-duration $-\mathrm{PA}$ events throughout the NH. Nearly all of these occur in summer (Figs. 10 and 11). We speculate that the tendency for long-lived -PA events in the Arctic is in part due to limited diabatic heating from convective and radiative sources there relative to midlatitude locations, allowing negative height anomalies to decay more slowly in the Arctic. Persistent tropopause-based Arctic cyclones were studied in depth by Cavallo and Hakim (2010, 2012), who demonstrate that radiative cooling is critical to their maintenance. Long-duration + PA events occur predominantly in the midlatitudes, 
(a) +PA NH Annual

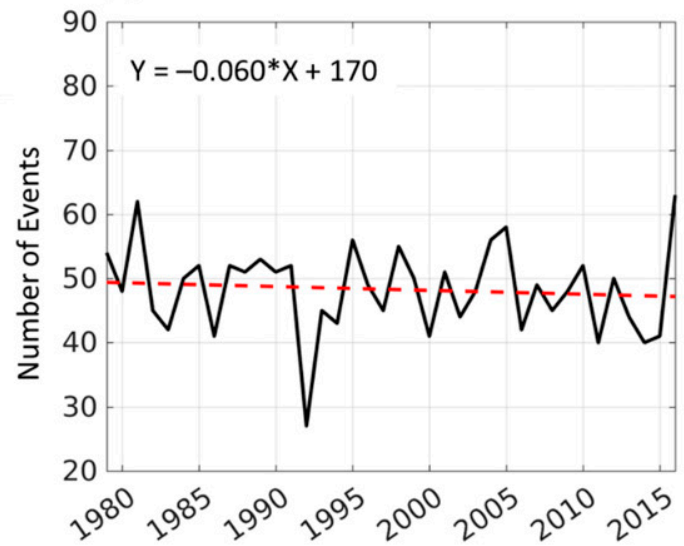

(c) +PA Arctic summer

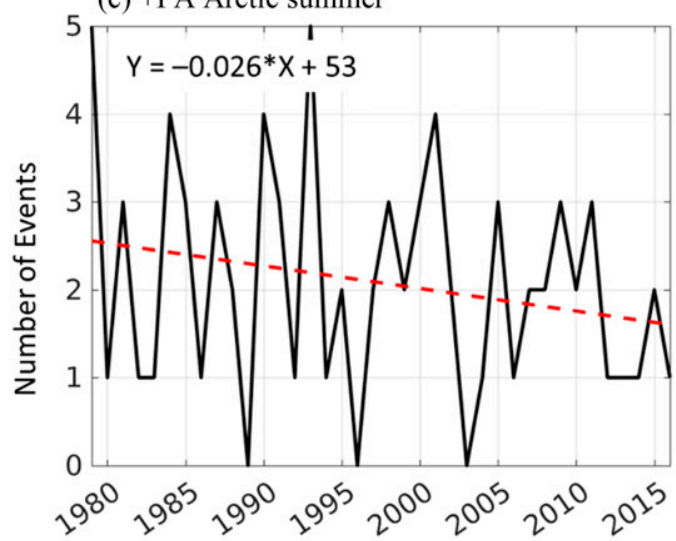

FIG. 7. Positive and negative PA event trends for the ERAI period of record. (a),(b) NH, (c), (d) Arctic summertime, and (e) Atlantic fall. Number of events each year (black line) and linear trend line (red dashed line) labeled. (b) -PA NH Annual

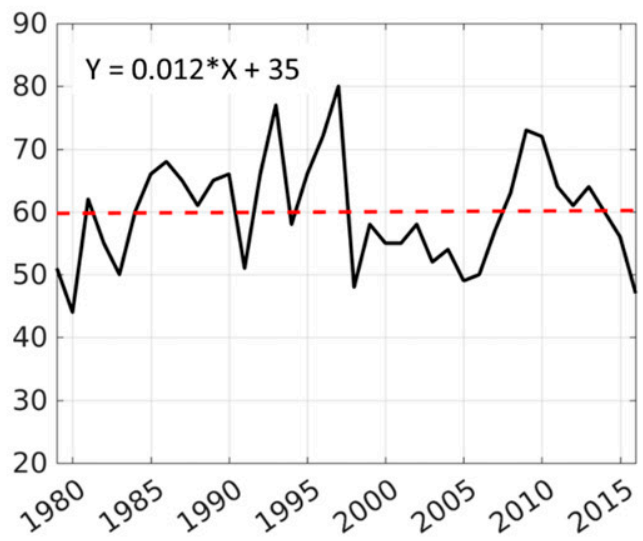

(d) -PA Arctic summer

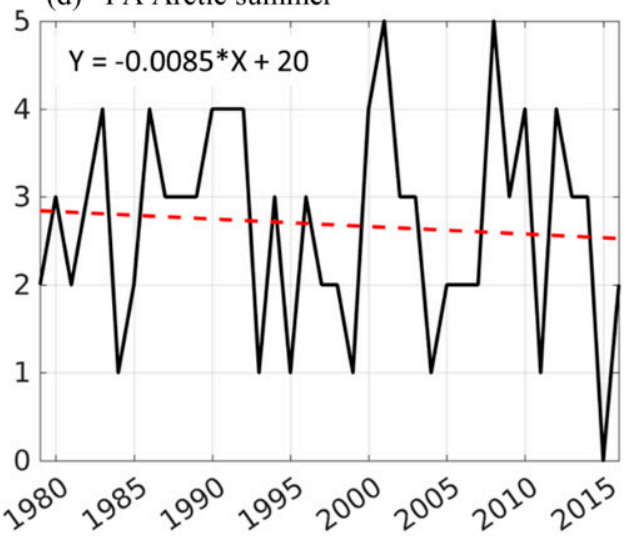

(e) -PA Atlantic fall

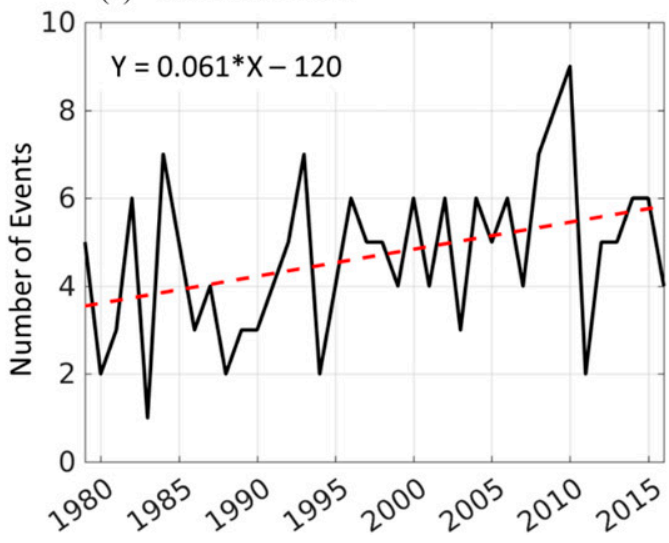

balanced synoptic-scale flow documented in prior studies (Hakim and Canavan 2005). The Pacific PA region experiences the largest spatial extent of both positive and negative PA events (Table 2), specifically, the most very large (average extent exceeding $3 \times 10^{6} \mathrm{~km}^{2}$ ) $+\mathrm{PA}$ events compared to any other region (see Miller 2019, Fig. 3.10). Conversely, the Arctic experiences the fewest events with large spatial extents; Arctic events are generally smaller in extent than events in all other regions. 

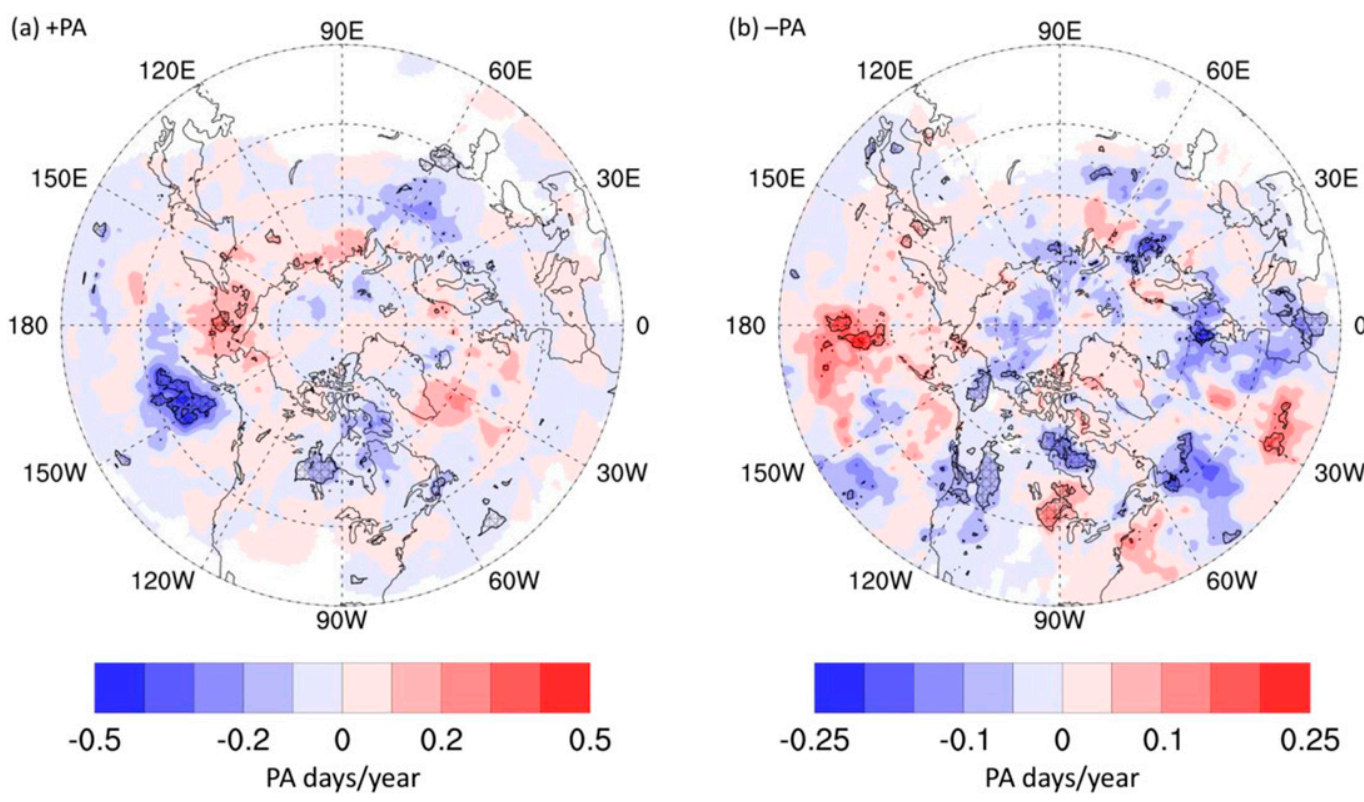

FIG. 8. Spatial distribution of positive and negative trends in PA days per year over the ERAI time series. (a) + PA and (b) $-\mathrm{PA}$. Black contours with hatch fill identify trends with a $p$ value $<0.05$.

Using the combined strength metric (the product of average magnitude and extent), we examine median event strength versus duration (Fig. 12). Strong, longlasting events are found in the midlatitudes during winter. The median $-\mathrm{PA}$ strength is weaker than for $+\mathrm{PA}$ events. For both $+\mathrm{PA}$ and $-\mathrm{PA}$ events, the long-lasting summer events are weaker than their wintertime counterparts (also see Miller 2019, section 3.2.2). Interestingly, a clear tendency for more persistent events to be stronger, which is present for both positive and negative events, is found only in the winter outside the Arctic.

\section{d. Arctic PAs}

The Arctic PA maximum (Figs. 3, 4c, and 5c) is not apparent in analyses using several other blocking definitions, which tend to focus more on the storm track regions. Recently, Arctic blocking has been studied by Pfahl et al. (2015) and Wernli and Papritz (2018), who use the PV-anomaly detection methods of Schwierz et al. (2004). A study by Pfahl and Wernli (2012) found a stronger summertime frequency maximum for Arctic blocks when using the ERA-Interim reanalysis relative to the coarser ERA-40. This summer Arctic maximum is also apparent in results presented by Dunn-Sigouin and Son (2013) using a combination of DG83 and Tibaldi and Molteni (1990) identification methods. Arctic PAs are found to contribute to the summertime anticyclonic circulation anomalies observed during summers with strongly reduced Arctic sea ice (e.g., Wernli and Papritz 2018). (a) +PA Events

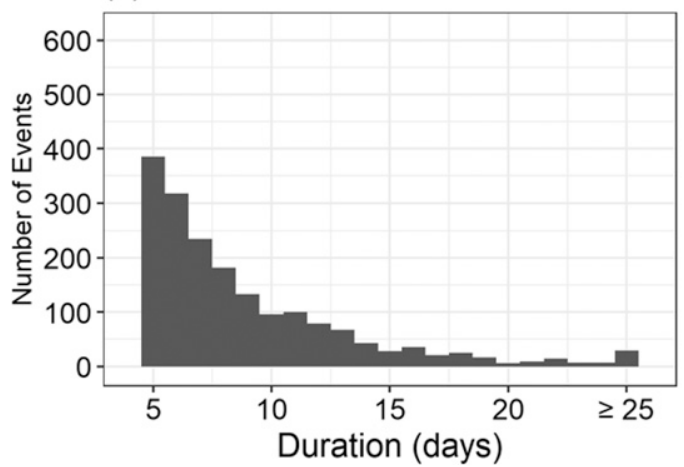

\section{(b) -PA Events}

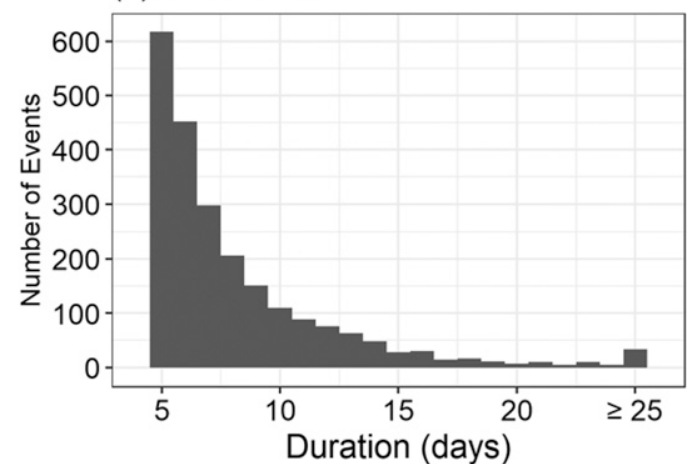

FIG. 9. Duration data for all Northern Hemisphere PA events: (a) +PA and (b) -PA. 
(a) Arctic +PA

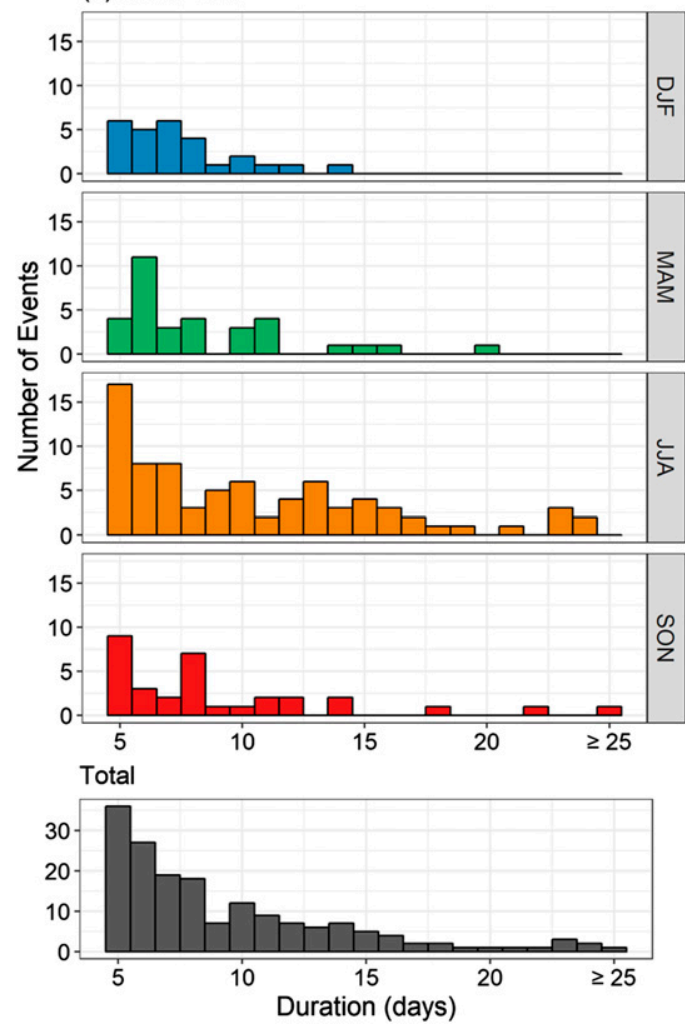

(b) Arctic -PA

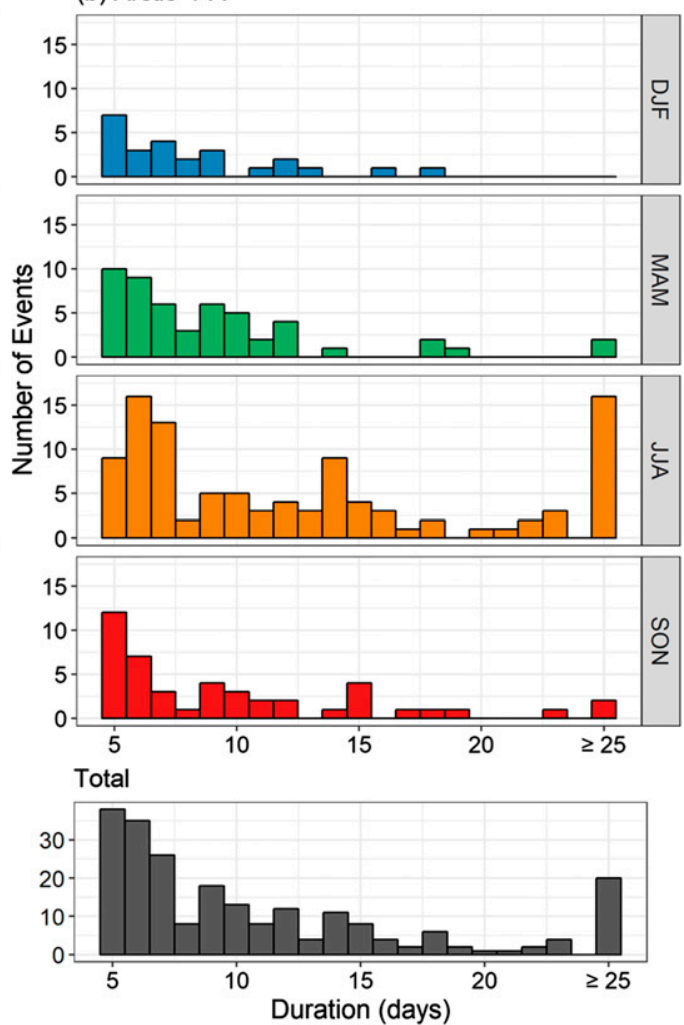

FIG. 10. Arctic \pm PA event duration histograms by season. (a) +PA events and (b) -PA events.

Using backward trajectories, Wernli and Papritz (2018) show that the anticyclones that contribute to the Arctic anomaly result from the injection of anomalously low-PV air into the Arctic upper troposphere. Climate warming, which features increased precipitation and condensational heating, may result in increased diabatic reduction of PV downstream of heavy precipitation (e.g., Keller 2017; Jung and Lackmann 2019). Events such as these could potentially be associated with trends in Arctic PA frequency.

A region of larger geopotential height standard deviation in the Arctic has been identified in the literature as standard deviation maxima at the 500and 700-hPa levels (Blackmon et al. 1984; Barnston and van den Dool 1993). The Arctic maximum was not apparent in DG83 because their analysis excluded summer months. The summertime $+\mathrm{PA}$ maximum evident over the Arctic Ocean in Fig. 4c is located poleward of the location of maximum surface anticyclone frequency identified by Reed and Kunkel (1960). There is likely a connection between the Arctic + PA maximum and the Beaufort Sea anticyclone analyzed by Serreze and Barrett (2011). Comprehensive analysis of the characteristics and processes associated with tropopause-based Arctic cyclones, which likely comprise some of our Arctic - PA cases, is presented by Cavallo and Hakim (2009, 2010, 2012, 2013). Here, we examine the structure and

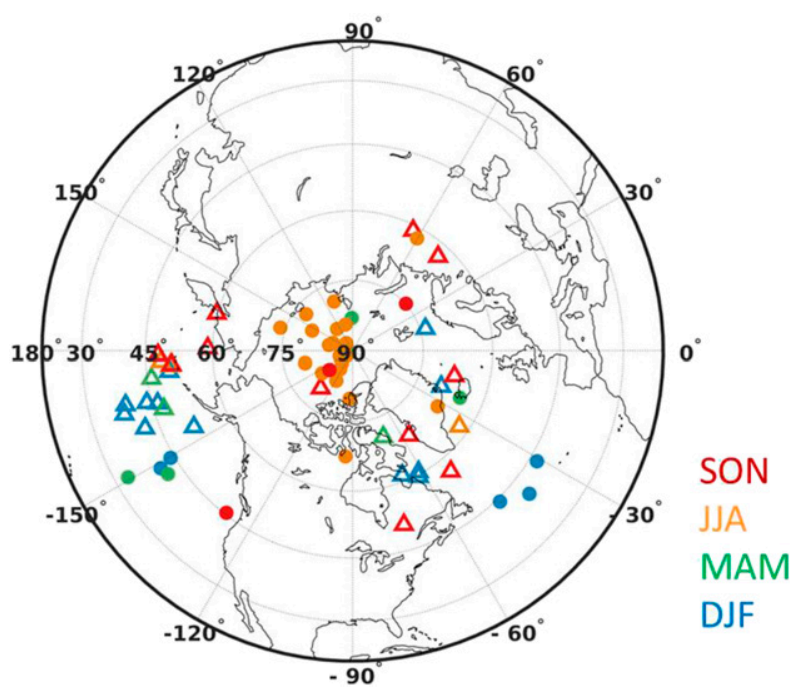

FIG. 11. Centroid location of long-duration ( $>25$ day) \pm PA events colored by season with + PA indicated by triangles and $-\mathrm{PA}$ indicated by circles. 
TABLE 2. Annual spatial extent percentiles (5th and 95th) $\left(\mathrm{km}^{2}\right)$ of the total number of events for the $\mathrm{NH}$ and regions.

\begin{tabular}{lccccc}
\hline \hline & \multicolumn{2}{c}{+ PA } & & \multicolumn{2}{c}{- PA } \\
\cline { 2 - 3 } \cline { 5 - 6 } & 5 th & 95 th & & 5 th & 95 th \\
\hline NH & $2.31 \times 10^{4}$ & $2.17 \times 10^{6}$ & & $1.00 \times 10^{4}$ & $1.20 \times 10^{6}$ \\
Pacific & $3.01 \times 10^{4}$ & $2.65 \times 10^{6}$ & & $1.29 \times 10^{4}$ & $1.47 \times 10^{6}$ \\
Atlantic & $2.37 \times 10^{4}$ & $2.07 \times 10^{6}$ & & $1.11 \times 10^{4}$ & $1.08 \times 10^{6}$ \\
Russia & $2.98 \times 10^{4}$ & $1.94 \times 10^{6}$ & & $8.70 \times 10^{3}$ & $1.29 \times 10^{6}$ \\
Arctic & $1.65 \times 10^{4}$ & $1.70 \times 10^{6}$ & & $6.00 \times 10^{3}$ & $7.25 \times 10^{5}$ \\
\hline
\end{tabular}

evolution of the Arctic PA maximum via a composite analysis of 34 summer Arctic +PA events (anticyclones).

Event magnitude averaged over the entire event lifetime is one measure of the integrated dynamical strength of the PA events. As expected, the seasonal distribution of the magnitude of Arctic PA events tends to mimic the seasonal variation in the PA magnitude threshold, with the lowest magnitude values occurring in summer, and the highest values in winter (Fig. 13). It is apparent that the dominant season for Arctic PA activity of either sign is summer (Fig. 13). Although the Arctic experiences a peak in events during summer, the highest event magnitudes are still reached in winter, consistent with a larger event threshold then.

The Arctic + PA event composite, developed as described in section $2 \mathrm{c}$, features a strong positive anomaly located over the region of the observed PA frequency maximum (Figs. 4c and 14). Closed geopotential height contours are identified at both the 500- and $300-\mathrm{hPa}$ level at peak magnitude (Figs. 14c,g). The Arctic +PA composite also exhibits a positive $\theta_{\text {Trop }}$ anomaly $\left(\theta_{\text {Trop }}^{\prime}\right)$ approaching $10 \mathrm{~K}$ in strength (Figs. $14 \mathrm{e}-\mathrm{h}$ ); this value is comparable to that found for Arctic anticyclones by Hakim and Canavan (2005). In the lower troposphere, the composite event features a center of high SLP (Figs. 14b-d), consistent with an equivalent barotropic structure.

At onset (day 1), the Arctic + PA composite exhibits positive $500-\mathrm{hPa}$ geopotential height and $\theta_{\text {Trop }}^{\prime}$ (e.g., low PV) anomalies as expected (Figs. 14b,f). There is also slightly higher SLP and a 500-hPa geopotential height ridge extending from over North America. There is a swath of positive $\theta_{\text {Trop }}^{\prime}$ over western North America, coincident with the 500-hPa ridge. Analysis of each individual event comprising the composite reveals that $62 \%$ (21 of 34 ) of the events feature a $500-\mathrm{hPa}$ geopotential height ridge extending from North America.

The lagged composite evolution, beginning 5 days prior to PA onset, reveals a gradual amplification of the composite height anomaly; this is in part due to a reduction in spread within the composite sample as the lag decreases (not shown). There is also a slight building or extension of a ridge over North America, most apparent 1 day prior to the event (Figs. 14a,e). Following the recent study of Wernli and Papritz (2018), who documented an influx of diabatically increased $\theta_{\text {Trop }}$ in Arctic blocking events, we calculate and composite the advection of $\theta_{\text {Trop }}\left(\theta_{\text {Trop_ADV }}\right)$ leading up to these events (Figs. 15 and 16). For reference, $\theta_{\text {Trop_ADV }}$ averaged over the Arctic
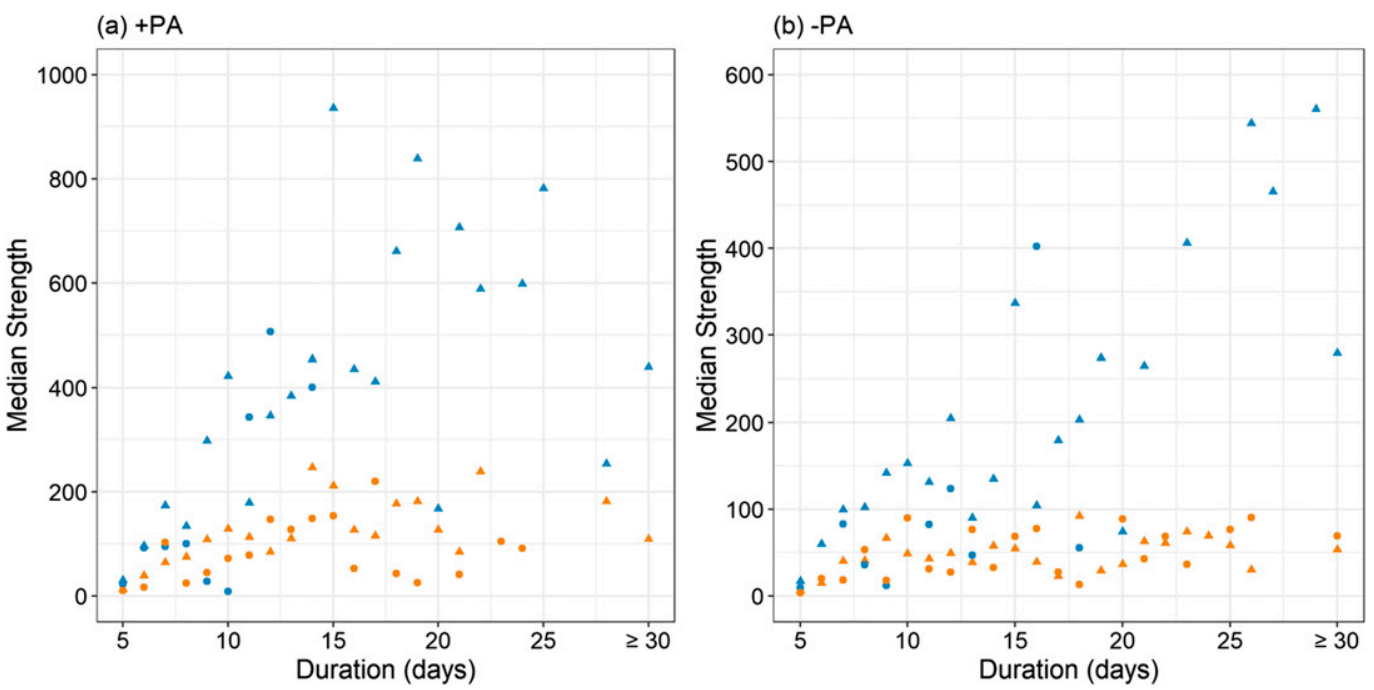

FIG. 12. Median strength by duration for (a) positive and (b) negative PA events where strength is defined as the product of the event average magnitude (gpm) and the event average spatial extent $\left(\times 10^{6} \mathrm{~km}^{2}\right)$. Winter (blue), summer (orange), Arctic events (dots), and midlatitude events (triangles). 
(a) Arctic +PA

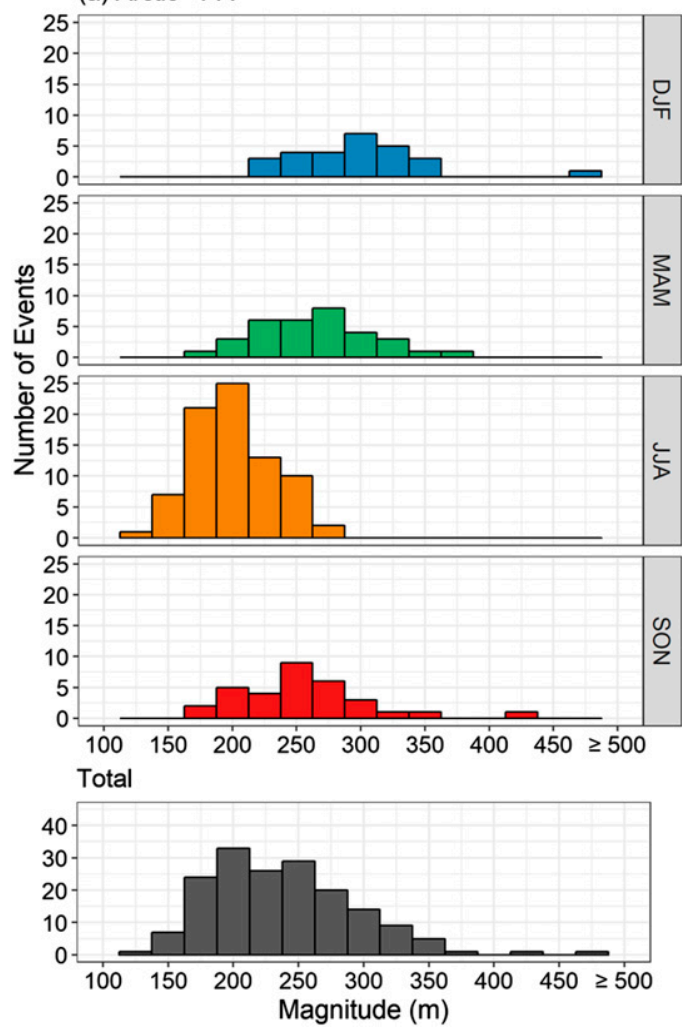

(b) Arctic -PA

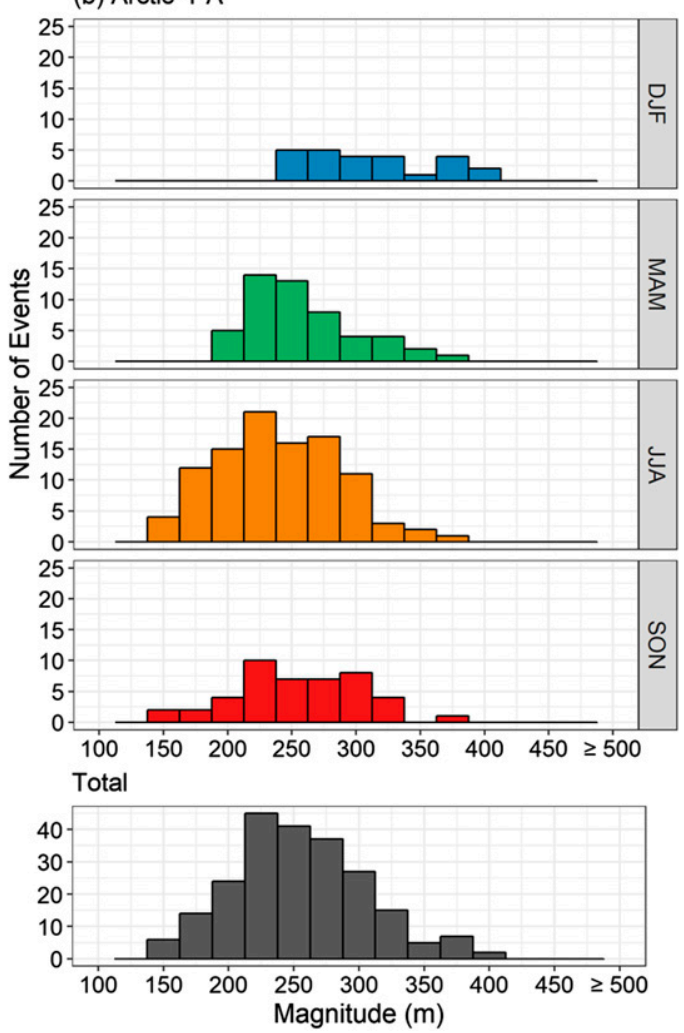

FIG. 13. Arctic \pm PA event maximum magnitude histograms by season. (a) +PA events and (b) $-\mathrm{PA}$ events.

region during the period of the composite event is $0.5 \times 10^{-5} \mathrm{~K} \mathrm{~s}^{-1}$. Despite large case-to-case variability, there is evidence for positive $\theta_{\text {Trop_ADV }}$ into the composite PA event region even 8 days prior to event onset (Fig. 15a). After onset, the averaged $\theta_{\text {Trop_ADV }}$ decreases to about zero on the day of peak magnitude. The cumulative sum of $\theta_{\text {Trop_ADV }}$, which accommodates case-to-case variations in the timing of high- $\theta_{\text {Trop }}$ influxes, exhibits an integrated buildup

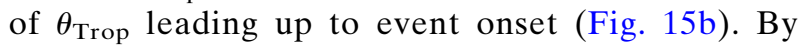
the time of peak event magnitude, however, daily $\theta_{\text {Trop_ADV }}$ in the PA region has returned to near zero (Fig. 15a), while the cumulative advection yields a positive $\theta_{\text {Trop }}^{\prime}$ of $\sim 10 \mathrm{~K}$, similar to that evident in the composite (Fig. 14g), and comparable to tropopause potential temperature anomalies found for Arctic anticyclones by Hakim and Canavan (2005). This suggests that advective transport is likely the primary source of low-PV air in these events, consistent with the findings of Wernli and Papritz (2018). A spatial view of the $\theta_{\text {Trop }}$ influx exhibits strong positive $\theta_{\text {Trop_ADV }}$ in the Arctic PA region (Fig. 16b). From day -3 to event onset there is continuous positive $\theta_{\text {Trop_ADV }}$, but with a lull around day -4 (Figs. 15a and 16c). At days -1 and 1 , strong positive $\theta_{\text {Trop_ADV }}$ is again seen within the
Arctic PA region (Figs. 16d,e). On the day of peak magnitude, the PA region is characterized by an approximate balance of negative and positive $\theta_{\text {Trop_ADV }}$ (Fig. 16f).

It is somewhat surprising that the influx of low-PV air into the Arctic PA region is evident so far in advance of event onset. This suggests that at least some Arctic PAs arise from sequential, episodic transport of low-PV air, eventually resulting in the development of a PA. However, the large standard deviation prior to day -5 (Fig. 15b) illustrates that there is significant case-to-case variability.

\section{Discussion and summary}

Although PA events and blocking are not identical, an advantage of an anomaly-based definition, such as DG83, over those requiring a gradient reversal is its ability to capture the full life cycle of events (Fig. 1; Schwierz et al. 2004). In this study, we extend the DG83 method by adopting a seasonally variable event magnitude threshold, in order to identify PAs in the geopotential height field throughout the year. This allows additional analysis of seasonal variations in PA characteristics and 
facilitates identification of warm-season PA features. Highly impactful PA events, such as heat waves and droughts (e.g., Matsueda 2011), occur in the summer, and thus we adopt a definition that permits the identification of such events.

We modified the fixed-magnitude threshold of DG83 based on the spatially averaged $\mathrm{NH}$ standard deviation of 500-hPa geopotential heights (Fig. 2). The MDG index is easy to apply because it only requires a single variable, the geopotential height, at a single isobaric level, $500 \mathrm{hPa}$. In addition to climatological studies, MDG could be applied to numerical model forecasts, for example in an ensemble prediction system, to forewarn of upcoming PA events. The MDG index would also be well suited to verification studies that measure the predictive skill of PAs in numerical forecasts.

Applying the modified index to the ERAI reanalysis, we identify four regions of PA frequency maxima: the North Pacific, North Atlantic, Russia, and the Arctic (Fig. 3). These PA regions are collocated with regional maxima in geopotential height standard deviation; both PA frequency and standard deviation exhibit strong seasonal variations (Figs. 4 and 5). While the midlatitude $\mathrm{PA}$ regions have been previously identified (e.g., DG83), the Arctic PA maximum, which occurs in summer, has not been analyzed extensively. Tropopause-based cyclones and anticyclones have been identified and examined by Hakim and Canavan (2005) and Cavallo and Hakim (2009, 2010), with an emphasis on Arctic events. However, our inclusion of a persistence requirement likely limits the overlap in their sample with our PA events. Despite differences in methods, both winter and summer +PA patterns (Fig. 4) are generally quite similar to patterns of blocking frequency shown by Pfahl and Wernli (2012, their Fig. 2), with the exception of a shift in the location of the summer Arctic frequency maximum. This feature is located in the Eastern Hemisphere in the Pfahl and Wernli study (their Fig. 2a), whereas our study identifies this feature in the Western Hemisphere (Fig. 4c).

It was necessary to detrend the geopotential height field prior to anomaly computation in order to identify dynamically meaningful PA features within a rising background height field. We find no significantly robust trends in the number, strength, spatial extent, or duration of positive or negative PA events over the 38 years of the ERAI reanalysis for the Northern Hemisphere, for the various subregions, and for the Arctic summertime PA maximum (Fig. 7). On seasonal time scales, however, we identified a positive trend in the North Atlantic during fall for negative PA events. The spatial distribution of PA-day trends over the 38-yr time series exhibits regional variability, including a poleward shift in +PA activity from the Gulf of Alaska to over the Bering Sea (Fig. 8a).

In all seasons, for positive and negative PAs, their occurrence roughly follows the distribution of geopotential variance. The patterns of PA occurrence are broadly similar for positive and negative events, although, in general, there are more +PA than -PA days. This is as expected from the more rapid dissipation of positive potential vorticity (thus negative geopotential) anomalies (cf. Hoskins et al. 1985), and also owing to the larger spatial extent of $+\mathrm{PA}$ events (Table 2). This suggests that most PAs have no "special" dynamics, but rather are manifestations of the high-amplitude low-frequency tails of a broad spectrum of atmospheric macroturbulence. The association between PAs and generic low-frequency variability is expected, in that imposing the requirement of a given duration (5-days is used throughout this study) acts roughly as a low-pass filter on geopotential heights. Consistent with this interpretation, maxima in the frequencies of PA occurrence are found to the east of maxima in overall day-to-day geopotential variance. Thus, we find a strong correspondence between the wintertime frequency of positive PAs (Fig. 4a) and maxima in the wintertime 10-60 day bandpass geopotential root-mean-square variance obtained by Kushnir and Wallace (1989), though it should be noted this correspondence is weaker for - PA events. As has been shown by many authors (e.g., Wallace and Gutzler 1981) low-frequency variability in the extratropics projects onto a set of teleconnection patterns, the temporal behavior of which tend to match red noise processes, with $e$-folding time scales on the order of seven to ten days (Feldstein 2000). Some portion of PA events should, therefore, be associated with the persistence of patterns such as the North Atlantic Oscillation (NAO) and Pacific-North American (PNA) pattern. This is what is found, in that the maximum in the wintertime frequency of positive PA events in the North Pacific coincides with the location of the midbasin maximum in the PNA pattern and the maximum in the frequency of positive PA events in the North Atlantic occurs where the NAO has its sub-Arctic maximum. The occurrence of fewer negative than positive PA events in these regions is consistent with the observed negative skewness of the indices of both patterns found by Johansson (2007). Additionally, Renwick and Wallace (1996) showed that 

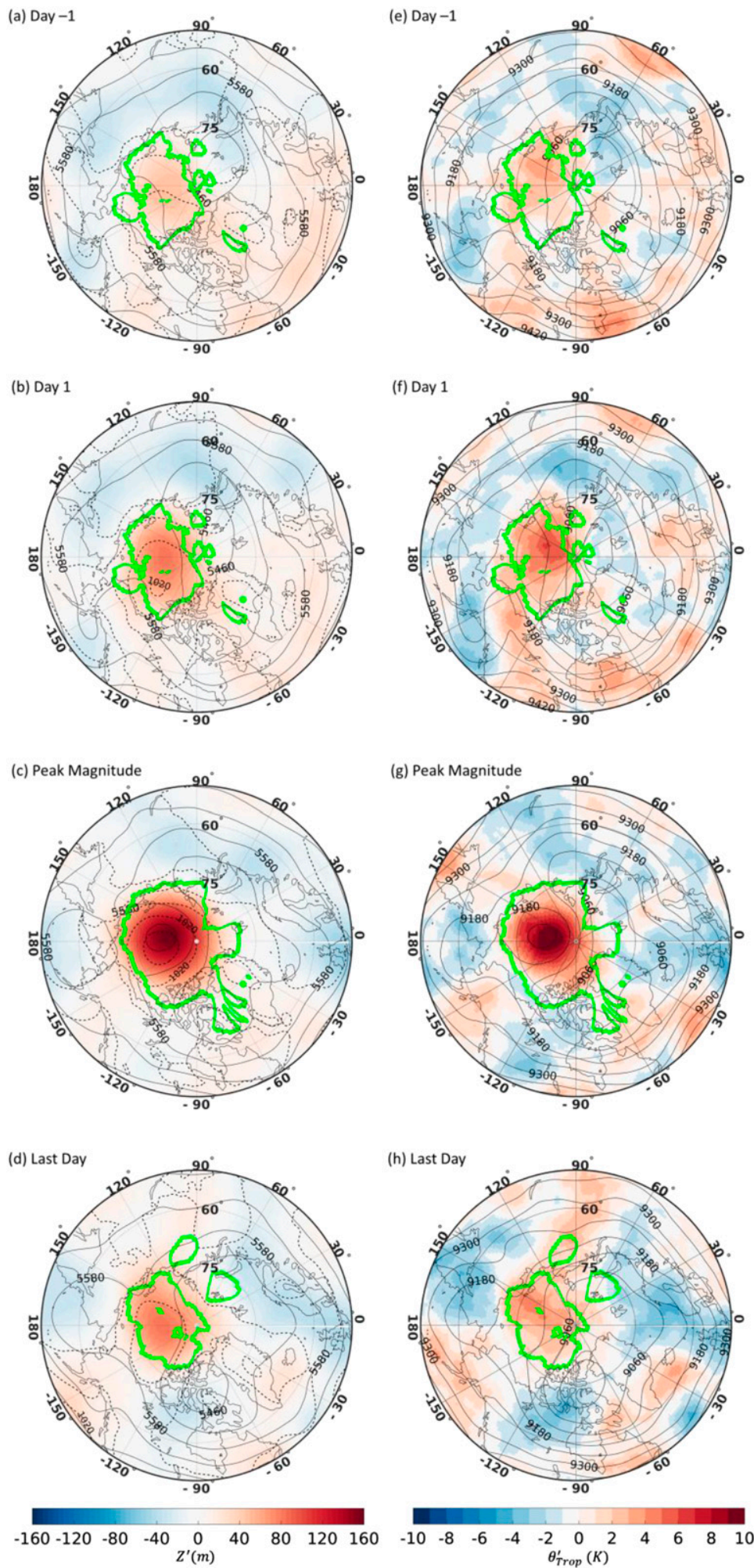

FIG. 14. Composited Arctic summer +PA events. (a),(e) 1 day prior to event onset; (b),(f) event onset, day 1; (c),(g) peak magnitude; and (d),(h) last day of PA event. (left) 500-hPa geopotential height anomaly (gpm, shaded as in legend), 500-hPa geopotential height (solid line, contour interval $60 \mathrm{gpm}$ ), and sea level pressure (dashed line, every $4 \mathrm{hPa}$ ). (right) Dynamic tropopause potential 
(a)

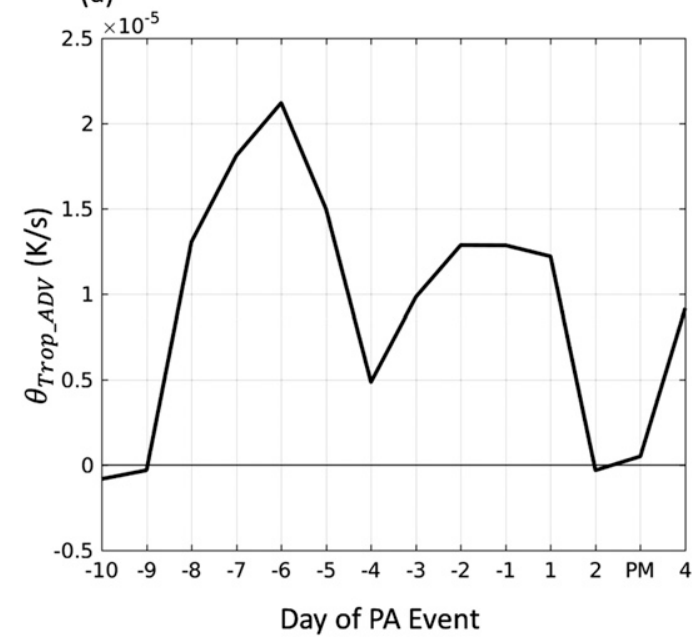

(b)

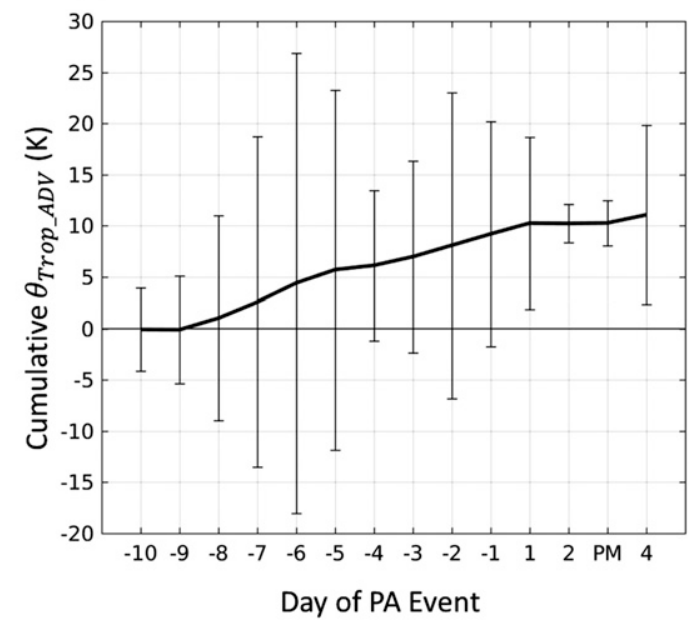

FIG. 15. Integrated $\theta_{\text {Trop_ADV }}$ for the composite Arctic PA event region (the composite extent of the + PA events listed in Table 1). (a) Daily integration and (b) cumulative sum. Error bars represent $1 \sigma$. Days less than zero indicate days prior to event onset (defined as day 1); day of peak magnitude is denoted "PM," and all days after PM are denoted " 4. "

North Pacific blocking events were associated with the negative phase of the PNA. Possible exceptions, however, to a view that PAs are a sample of generic low-frequency variability are the existence of concentrations of unusually persistent events, with lifetimes longer than 25 days: positive events in the subpolar Atlantic and midlatitude Pacific in winter, and negative events in the Arctic in summer (Fig. 11). Such persistence suggests that positive feedback mechanisms are operating. These could be interactions with transient eddies in the storm tracks (e.g., Shutts 1983), while, in the summertime Arctic, radiative processes (e.g., Cavallo and Hakim 2012, 2013) or surface energy fluxes may contribute (e.g., Serreze and Barry 2011).

In addition to presentation of seasonal variations in PA activity, another novel aspect of our analysis is the summertime Arctic PA maximum. This region is distinct from the midlatitude PA regions because it is spatially separated from the midlatitude storm track, where synoptic transients can initiate and maintain PA events (e.g., Shutts 1983; Nakamura et al. 1997; Altenhoff et al. 2008). As noted by the early study of
Reed and Kunkel (1960), however, baroclinic wave activity over the Arctic Ocean is associated with a high-latitude storm track there. Consistently, collocated with the Arctic PA maximum is a region of greater variability, which has been identified in the literature as a standard deviation maximum at the 500- and 700-hPa levels (Blackmon et al. 1984; Barnston and van den Dool 1993). More recently, blocking in the Arctic region has been studied by Pfahl et al. (2015), who use the PV-anomaly detection methods of Schwierz et al. (2004). This maximum is also apparent in Dunn-Sigouin and Son (2013) using a combination of DG83 and Tibaldi and Molteni (1990) identification methods.

A composite of 34 Arctic summertime +PA events exhibits an equivalent barotropic structure (Fig. 14), similar to that found for midlatitude PAs. Following Wernli and Papritz (2018), who documented an influx of diabatically increased $\theta_{\text {Trop }}$ in Arctic blocking events, we calculate and composite the advection of $\theta_{\text {Trop }}$ leading up to these PA events (Figs. 15 and 16). We find an influx of positive advection in the week leading up to event onset, suggesting a significant

$\longleftarrow$

temperature anomaly (K, shaded as in legend) and 300-hPa geopotential height (solid line, contour interval $60 \mathrm{gpm}$ ). Green contour represents the composite PA spatial extent, comprising the outline of 34 events for the day 1 composite in (a),(b),(e),(f); in (c),(g), green contour is composite PA outline for the day of peak magnitude; in (d),(h), green contour is composite PA outline for the last day of the event. 

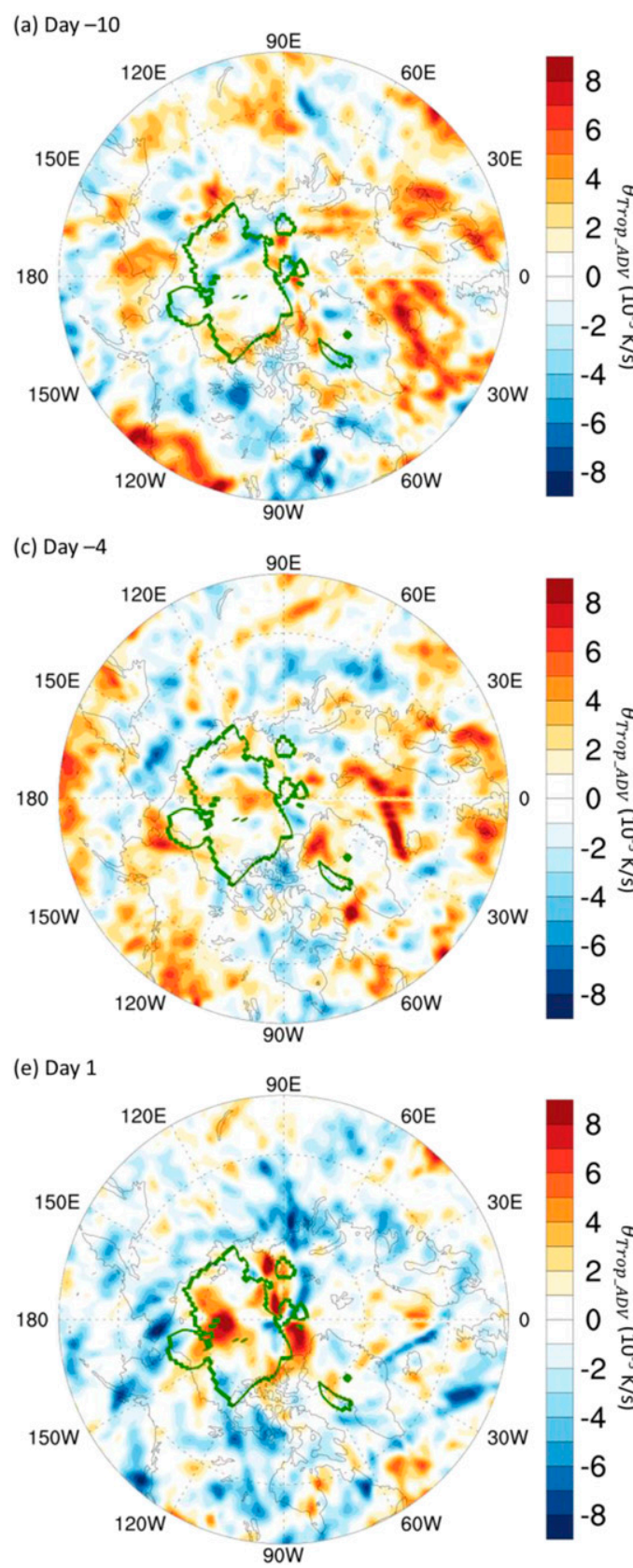

(b) Day-6

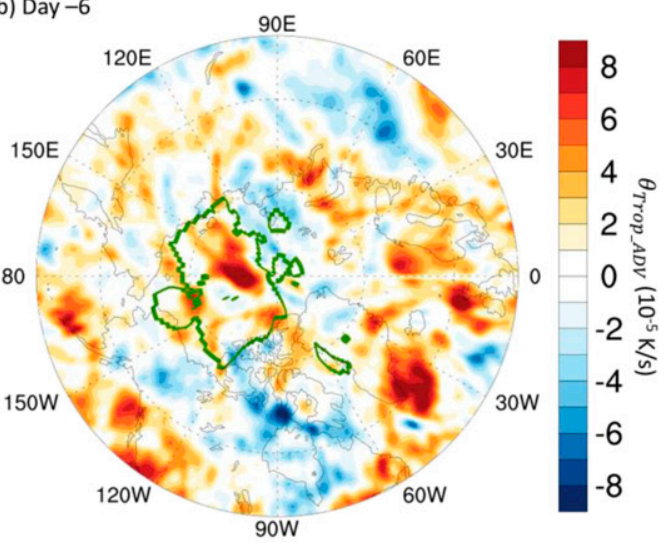

(d) Day -1
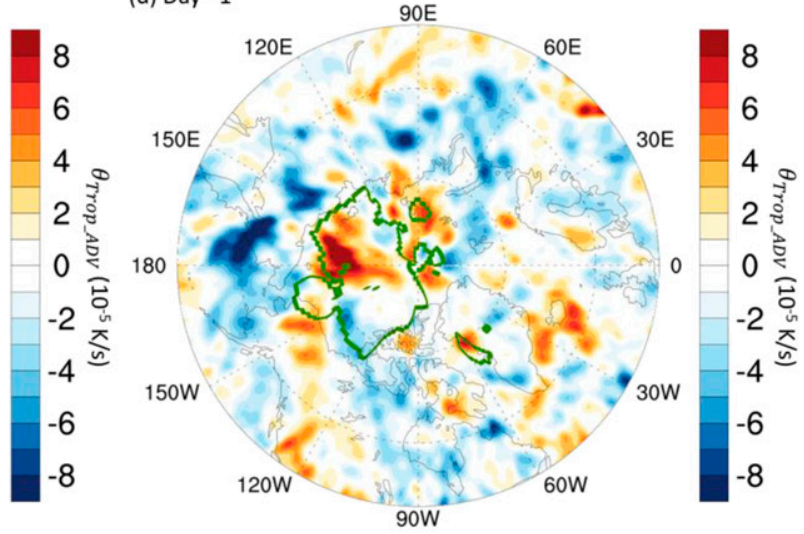

(f) Peak Magnitude

$90 \mathrm{E}$
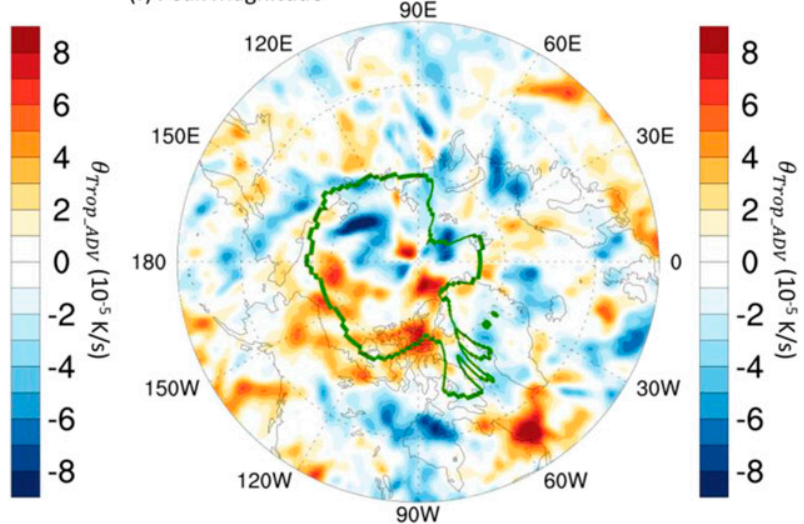

FIG. 16. Advection of $\theta_{\text {Trop }}\left(\theta_{\text {Trop_ADV }}\right)$. The composite event PA footprint is contoured (green) to represent (a)-(e) day 1 and (f) the day of peak magnitude.

role for diabatic input from lower latitudes consistent with Wernli and Papritz (2018). ${ }^{4}$

Additional work is needed to better understand the dynamical mechanisms of the Arctic PA maximum

\footnotetext{
${ }^{4}$ Additional analysis would be required to quantify the relative contributions of diabatic and adiabatic processes to the transport of low-PV air.
}

and their relation to changes in Arctic sea ice extent. More generally, given the connection between PAs and extreme weather events, it is imperative to understand how the increase in greenhouse gases and rising global temperatures may affect PAs in the future. The current generation of general circulation models struggles to adequately represent present-day PAs (e.g., Scaife et al. 2010; Masato et al. 2013; Hoskins and Woollings 2015; Woollings et al. 2018). 
In a subsequent paper, we will apply the modified index to high-resolution global climate simulations in order to explore the question of how PAs may change in a warming climate.

Acknowledgments. This research was supported by NSF Grant AGS-1560844, awarded to North Carolina State University (NCSU). We acknowledge the European Centre for Medium-Range Weather Forecasts (ECMWF) for the ERA-Interim gridded data, which were obtained through the National Center for Atmospheric Research (NCAR) Computational and Information Systems Lab (CISL) facility. The NC State HPC facility is acknowledged for their role in this project. Editor Dr. David Schultz and three anonymous reviewers provided thorough and constructive comments during the peer-review process. We wish to thank Drs. Anantha Aiyyer and Greg Tierney for their support and suggestions during this project. This paper represents a portion of the first author's MS thesis.

\section{REFERENCES}

Altenhoff, A. M., O. Martius, M. Croci-Maspoli, C. Schwierz, and H. C. Davies, 2008: Linkage of atmospheric blocks and synoptic-scale Rossby waves: A climatological analysis. Tellus, 60A, 1053-1063, https://doi.org/10.1111/j.16000870.2008.00354.x.

American Meteorological Society, 2019: Blocking. Glossary of Meteorology, http://glossary.ametsoc.org/wiki/blocking.

Barnston, A. G., and R. E. Livezey, 1987: Classification, seasonality, and persistence of low-frequency atmospheric circulation patterns. Mon. Wea. Rev., 115, 1083-1126, https://doi.org/ 10.1175/1520-0493(1987)115<1083:CSAPOL > 2.0.CO;2.

— causes of low-frequency variability: The interannual standard deviation of monthly mean 700-mb height. J. Climate, $\mathbf{6}$, 2083-2102, https://doi.org/10.1175/1520-0442(1993)006<2083: TUTCOL $>2.0 . \mathrm{CO} ; 2$.

Barriopedro, D., R. Garcia-Herrera, and R. M. Trigo, 2010: Application of blocking diagnosis methods to General Circulation Models. Part I: A novel detection scheme. Climate Dyn., 35, 1373-1391, https://doi.org/10.1007/s00382-010-0767-5.

—, E. Fischer, J. Luterbacher, R. Trigo, and R. García-Herrera, 2011: The hot summer of 2010: Redrawing the temperature record map of Europe. Science, 332, 220-224, https://doi.org/ 10.1126/science.1201224.

Blackmon, M. L., Y. H. Lee, and J. M. Wallace, 1984: Horizontal structure of $500 \mathrm{mb}$ height fluctuations with long, intermediate, and short time scales. J. Atmos. Sci., 41, 961-980, https://doi.org/ 10.1175/1520-0469(1984)041<0961:HSOMHF>2.0.CO;2.

Cavallo, S. M., and G. J. Hakim, 2009: Potential vorticity diagnosis of a tropopause polar cyclone. Mon. Wea. Rev., 137, 13581371, https://doi.org/10.1175/2008MWR2670.1.

—_, and — 2010: Composite structure of tropopause polar cyclones. Mon. Wea. Rev., 138, 3840-3857, https://doi.org/ 10.1175/2010MWR3371.1.
— and - 2012: Radiative impact on tropopause polar vortices over the Arctic. Mon. Wea. Rev., 140, 1683-1702, https:// doi.org/10.1175/MWR-D-11-00182.1.

— , and —, 2013: Physical mechanisms of tropopause polar vortex intensity change. J. Atmos. Sci., 70, 3359-3373, https:// doi.org/10.1175/JAS-D-13-088.1.

Croci-Maspoli, M., C. Schwierz, and H. C. Davies, 2007: A multifaceted climatology of atmospheric blocking and its recent linear trend. J. Climate, 20, 633-649, https://doi.org/10.1175/ JCLI4029.1.

Dee, D. P., and Coauthors, 2011: The ERA-Interim reanalysis: Configuration and performance of the data assimilation system. Quart. J. Roy. Meteor. Soc., 137, 553-597, https://doi.org/ 10.1002/qj.828.

Dole, R. M., 1982: Persistent anomalies of the extratropical Northern Hemisphere wintertime circulation. Ph.D. dissertation, Massachusetts Institute of Technology.

, and N. D. Gordon, 1983: Persistent anomalies of the extratropical Northern Hemisphere wintertime circulation: Geographical distribution and regional persistence characteristics. Mon. Wea. Rev., 111, 1567-1586, https://doi.org/10.1175/15200493(1983)111<1567:PAOTEN>2.0.CO;2.

- , and Coauthors, 2011: Was there a basis for anticipating the 2010 Russian heat wave? Geophys. Res. Lett., 38, L06702, https://doi.org/10.1029/2010GL046582.

Dunn-Sigouin, E., and S. W. Son, 2013: Northern Hemisphere blocking frequency and duration in the CMIP5 models. J. Geophys. Res. Atmos., 118, 1179-1188, https://doi.org/ 10.1002/jgrd.50143.

Feldstein, S. B., 2000: The timescale, power spectra, and climate noise properties of teleconnection patterns. J. Climate, 13, 4430-4440, https://doi.org/10.1175/1520-0442(2000)013<4430: TTPSAC $>2.0 . \mathrm{CO} ; 2$.

Francis, J. A., and S. J. Vavrus, 2015: Evidence for a wavier jet stream in response to rapid Arctic warming. Environ. Res. Lett., 10, 014005, https://doi.org/10.1088/1748-9326/10/1/014005.

Grams, C. M., R. Beerli, S. Pfenninger, I. Staffell, and H. Wernli, 2017: Balancing Europe's wind-power output through spatial deployment informed by weather regimes. Nat. Climate Change, 7, 557-562, https://doi.org/10.1038/nclimate3338.

Green, J. S. A., 1977: The weather during July 1976: Some dynamical considerations of the drought. Weather, 32, 120-126, https://doi.org/10.1002/j.1477-8696.1977.tb04532.x.

Hakim, G. J., and A. K. Canavan, 2005: Observed cycloneanticyclone tropopause vortex asymmetries. J. Atmos. Sci., 62, 231-240, https://doi.org/10.1175/JAS-3353.1.

Hong, C.-C., H.-H. Hsu, N.-H. Lin, and H. Chiu, 2011: Roles of European blocking and tropical-extratropical interaction in the 2010 Pakistan flooding. Geophys. Res. Lett., 38, L13806, https://doi.org/10.1029/2011GL047583.

Hoskins, B. J., and T. Woollings, 2015: Persistent extratropical regimes and climate extremes. Curr. Climate Change Rep., $\mathbf{1}$, 115-124, https://doi.org/10.1007/s40641-015-0020-8.

_ A. J. Simmons, and D. G. Andrews, 1977: Energy dispersion in a barotropic atmosphere. Quart. J. Roy. Meteor. Soc., 103, 553-567, https://doi.org/10.1002/qj.49710343802.

— M. E. McIntyre, and A. W. Robertson, 1985: On the use and significance of isentropic potential vorticity maps. Quart. J. Roy. Meteor. Soc., 111, 877-946, https://doi.org/ 10.1002/qj.49711147002.

Johansson, A., 2007: Prediction skill of the NAO and PNA from daily to seasonal time scales. J. Climate, 20, 1957-1975, https:// doi.org/10.1175/JCLI4072.1. 
Jung, C., and G. M. Lackmann, 2019: Extratropical transition of Hurricane Irene (2011) in a changing climate. J. Climate, 32, 4847-4871, https://doi.org/10.1175/JCLI-D-18-0558.1.

Keller, J. H., 2017: Amplification of the downstream wave train during extratropical transition: Sensitivity studies. Mon. Wea. Rev., 145, 1529-1548, https://doi.org/10.1175/MWR-D-16-0193.1.

Kushnir, Y., and J. M. Wallace, 1989: Low-frequency variability in the Northern Hemisphere winter: Geographical distribution, structure, and time-scale dependence. J. Atmos. Sci., 46, 3122-3143, https://doi.org/10.1175/1520-0469(1989)046<3122: LFVITN $>2.0 . \mathrm{CO} ; 2$.

Masato, G., B. J. Hoskins, and T. Woollings, 2013: Winter and summer Northern Hemisphere blocking in CMIP5 models. J. Climate, 26, 7044-7059, https://doi.org/10.1175/JCLI-D12-00466.1.

Matsueda, M., 2011: Predictability of Euro-Russian blocking in summer of 2010. Geophys. Res. Lett., 38, L06801, https:// doi.org/10.1029/2010GL046557.

Miller, R. L., 2019: A modified persistent anomaly index applied to present and future climates. M.S. thesis. Dept. of Marine Earth and Atmospheric Sciences, North Carolina State University, $120 \mathrm{pp}$.

Nakamura, H., M. Nakamura, and J. L. Anderson, 1997: The role of high- and low- frequency dynamics in blocking formation. Mon. Wea. Rev., 125, 2074-2093, https://doi.org/10.1175/15200493(1997) $125<2074$ :TROHAL $>2.0$.CO;2.

NOAA/National Centers for Environmental Information, 2015a: State of the Climate: National climate report for February 2015. NOAA/NCEI, accessed 14 November 2018, https:// www.ncdc.noaa.gov/sotc/national/201502.

_ 2015b: State of the Climate: National climate report for March 2015. NOAA/NCEI, accessed 14 November 2018, https://www.ncdc.noaa.gov/sotc/national/201503.

Pelly, J. L., and B. J. Hoskins, 2003: A new perspective on blocking. J. Atmos. Sci., 60, 743-755, https://doi.org/10.1175/15200469(2003)060<0743:ANPOB > 2.0.CO;2.

Pfahl, S., and H. Wernli, 2012: Quantifying the relevance of atmospheric blocking for co-located temperature extremes in the Northern Hemisphere on (sub-)daily time scales. Geophys. Res. Lett., 39, L12807, https://doi.org/10.1029/2012GL052261.

- C. Schwierz, M. Croci-Maspoli, C. M. Grams, and H. Wernli, 2015: Importance of latent heat release in ascending air streams for atmospheric blocking. Nat. Geosci., 8, 610-614, https://doi.org/10.1038/ngeo2487.

Reed, R. J., and B. A. Kunkel, 1960: The Arctic circulation in summer. J. Meteor., 17, 489-506, https://doi.org/10.1175/15200469(1960)017<0489:TACIS >2.0.CO;2.

Renwick, J. A., and J. M. Wallace, 1996: Relationships between North Pacific wintertime blocking, El Nino, and the PNA pattern. Mon. Wea. Rev., 124, 2071-2076, https://doi.org/ 10.1175/1520-0493(1996)124<2071:RBNPWB>2.0.CO;2.

Rex, D. F., 1950a: Blocking action in the middle troposphere and its effect upon regional climate. I. An aerological study of blocking action. Tellus, 2, 196-211, https://doi.org/10.1111/ j.2153-3490.1950.tb00331.x.

,$- 1950 \mathrm{~b}$ : Blocking action in the middle troposphere and its effect upon regional climate. II. The climatology of blocking action. Tellus, 2, 275-301, https://doi.org/10.1111/j.21533490.1950.tb00339.x.

_ 1951: The effect of Atlantic blocking action upon European climate. Tellus, 3, 100-112, https://doi.org/10.3402/tellusa.v3i2.8617.

Robertson, D. G. E., and J. J. Dowling, 2003: Design and responses of Butterworth and critically damped digital filters. J. Electromyogr. Kinesiol., 13, 569-573, https://doi.org/ 10.1016/S1050-6411(03)00080-4.

Scaife, A. A., T. Woollings, J. Knight, G. Martin, and T. Hinton, 2010: Atmospheric blocking and mean biases in climate models. J. Climate, 23, 6143-6152, https://doi.org/10.1175/2010JCLI3728.1.

Schwierz, C., M. Croci-Maspoli, and H. C. Davies, 2004: Perspicacious indicators of atmospheric blocking. Geophys. Res. Lett., 31, L06125, https://doi.org/10.1029/2003GL019341.

Serreze, M. C., and A. P. Barrett, 2011: Characteristics of the Beaufort Sea high. J. Climate, 24, 159-182, https://doi.org/ 10.1175/2010JCLI3636.1.

— , and R. G. Barry, 2011: Processes and impacts of Arctic amplification: A research synthesis. Global Planet. Change, 77, 85-96, https://doi.org/10.1016/j.gloplacha.2011.03.004.

Shutts, G. J., 1983: The propagation of eddies in diffluent jetstreams: Eddy vorticity forcing of 'blocking' flow fields. Quart. J. Roy. Meteor. Soc., 109, 737-761, https://doi.org/10.1002/ QJ.49710946204.

Sillmann, J., M. Croci-Maspoli, M. Kallache, and R. W. Katz, 2011: Extreme cold winter temperatures in Europe under the influence of North Atlantic atmospheric blocking. J. Climate, 24, 5899-5913, https://doi.org/10.1175/2011JCLI4075.1.

Tibaldi, S., and F. Molteni, 1990: On the operational predictability of blocking. Tellus, 42A, 343-365, https://doi.org/10.3402/ tellusa.v42i3.11882.

Wallace, J. M., and D. S. Gutzler, 1981: Teleconnections in the geopotential height field during the Northern Hemisphere winter. Mon. Wea. Rev., 109, 784-812, https://doi.org/10.1175/ 1520-0493(1981)109<0784:TITGHF>2.0.CO;2.

Wernli, H., and L. Papritz, 2018: Role of polar anticyclones and midlatitude cyclones for Arctic summertime sea-ice melting. Nat. Geosci., 11, 108, https://doi.org/10.1038/s41561-017-0041-0.

Woollings, T., and Coauthors, 2018: Blocking and its response to climate change. Curr. Climate Change Rep., 4, 287-300, https:// doi.org/10.1007/s40641-018-0108-z. 